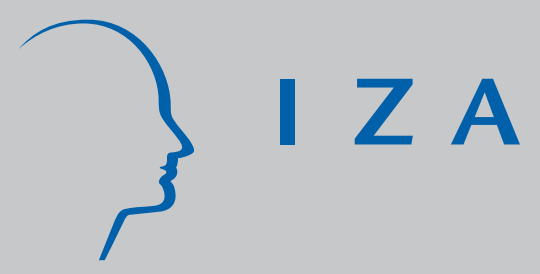

IZA DP No. 803

Social Interactions in Unemployment

Rafael Lalive

J une 2003 


\title{
Social Interactions in Unemployment
}

\author{
Rafael Lalive \\ Tinbergen Institute, CESifo \\ and IZA Bonn
}
Discussion Paper No. 803
June 2003

\author{
IZA \\ P.O. Box 7240 \\ D-53072 Bonn \\ Germany \\ Tel.: +49-228-3894-0 \\ Fax: +49-228-3894-210 \\ Email: iza@iza.org
}

This Discussion Paper is issued within the framework of IZA's research area Welfare State and Labor Market. Any opinions expressed here are those of the author(s) and not those of the institute. Research disseminated by IZA may include views on policy, but the institute itself takes no institutional policy positions.

The Institute for the Study of Labor (IZA) in Bonn is a local and virtual international research center and a place of communication between science, politics and business. IZA is an independent, nonprofit limited liability company (Gesellschaft mit beschränkter Haftung) supported by Deutsche Post World Net. The center is associated with the University of Bonn and offers a stimulating research environment through its research networks, research support, and visitors and doctoral programs. IZA engages in (i) original and internationally competitive research in all fields of labor economics, (ii) development of policy concepts, and (iii) dissemination of research results and concepts to the interested public. The current research program deals with (1) mobility and flexibility of labor, (2) internationalization of labor markets, (3) welfare state and labor market, (4) labor markets in transition countries, (5) the future of labor, (6) evaluation of labor market policies and projects and (7) general labor economics.

IZA Discussion Papers often represent preliminary work and are circulated to encourage discussion. Citation of such a paper should account for its provisional character. A revised version may be available on the IZA website (www.iza.org) or directly from the author. 
IZA Discussion Paper No. 803

June 2003

\section{ABSTRACT}

\section{Social Interactions in Unemployment ${ }^{*}$}

This paper studies the relevance of social interactions among the unemployed. Identification is based on a salient and selective extension of the potential duration of unemployment benefits. If social interactions are important, this policy change affects entitled individuals not only directly, but also indirectly by altering the duration of unemployment in the reference group. Moreover, this spillover effect of the policy should also be observed in the non-entitled group. Results indicate that there are strong indirect effects on the entitled, strong positive spillovers on the non-entitled, and that social interactions are about as important as the direct effects of the policy change.

JEL Classification: $\quad$ C41, J64, J65

Keywords: social interactions, social multiplier, unemployment, quasi-experiment

Rafael Lalive

Tinbergen Institute

Roeterstraat 31

1018 WB Amsterdam

The Netherlands

Email: rlalive@iew.unizh.ch

\footnotetext{
* Thanks to Robert Moffitt, Erzo F. P. Luttmer, Alois Stutzer, Chris Taber, and to seminar participants at Harvard, IFAU, Northwestern, and University of Amsterdam for valuable comments. Andreas Kuhn, Oliver Ruf, and Adrian Kienast provided superb research assistance. Financial support by the Swiss National Science Foundation (No. 8210-67640) is gratefully acknowledged.
} 


\section{Introduction}

This paper studies to what extent interactions among the unemployed may be relevant in labor supply. Individuals who are out of work may not only focus on their own well-being in reaching a choice regarding labor supply but also consider the way in which a group consisting of individuals in a similar life situation is dealing with unemployment. There are at least three reasons why such interactions among the unemployed can be important. First, the unemployed may learn from each other about the availability of jobs or about successful strategies in a job interview. Second, unemployment is associated with a strong increase in leisure. Arguably, the extent to which such leisure can be enjoyed depends on the manner in which the group's allocation of time between job search and leisure. Third, there is some evidence in social psychology that unemployment puts considerable stress on the relationships between the unemployed and the employed. This suggests that interactions among the unemployed may be as important as interactions between the employed and the unemployed. ${ }^{1}$

Social interactions may rationalize the strong degree of spatial variance in unemployment. For instance, the standard deviation of the unemployment rate across regions in Europe is roughly $50 \%$ of its mean level. Spatial variance also tends to be strong in tightly defined geographic units in the U.S. Whereas the coefficient of variation of the unemployment rate is about $20 \%$ across states, the standard deviation of the unemployment rate exceeds $80 \%$ of its mean level across census tracts in Chicago. Regional differences in the age and gender composition explain a relatively modest share of the total variance in unemployment rates (OECD, 2000). In contrast, even small differences in labor market conditions give rise to strong variance in unemployment if social interactions are strong. Second, information on the strength of social interactions is relevant for labor market policy. For instance, in order to predict the effects of a policy change it is essential to know the 'social geography' of a population if social interactions are important. Furthermore, social interactions prolong adjustment to changes in the structure of the labor market (Akerlof, 1997).

This paper argues that social interactions can be identified in a salient and selective change in the unemployment insurance system. In June 1988, the Austrian government extended the duration of regular unemployment benefits from 30 weeks to 209 weeks for workers aged 50 or older living in certain regions who spent at least 15 out of the previous 25 years in work. This regional extended benefits program (REBP) lowers the incentives to accept a regular job at the individual level. Furthermore, due to the selective nature of the entitlement criteria, the degree to which this program alters the group's unemployment duration depends on the group's

\footnotetext{
${ }^{1}$ See Corcoran et al. (1980), Granovetter, (1995), Montgomery (1991), Topa (2001), and Topa and Conley (2002) for studies that focus on interactions between the unemployed and the employed.
} 
composition with respect to age, previous work experience, and location of residence. If social interactions are important, the program affects entitled individuals not only directly, but also indirectly via the change in the group's average unemployment duration. Furthermore, there are also spillovers of this program on the individuals who are not entitled to the policy change. Thus, information on outcomes with a "partial-population intervention" allows identifying social interactions in labor supply (Moffitt, 2001). ${ }^{2}$

The empirical analysis is based on administrative data on the entire inflow into unemployment in the age group 48 to 51 in the period from 1986 until 1991. Because the data contain information on the identity of the previous employer, the reference group is defined to encompass all former workplace colleagues in the age bracket 45 to 54 who enter unemployment in the same period as the individual. This choice of reference group is motivated by the fact that individuals tend to regard the actions of other persons in the same age group as relevant. Furthermore, there is strong evidence that occupational relations are relevant in the labor market. Thus, the dataset provides detailed information on entitled individuals (aged 50-51) and non-entitled individuals (aged 48-49) at the interesting age threshold 50. Because the REBP is temporary and region specific, it is possible to separate the correlation of the outcome with group composition due to sorting from the correlation of the outcome with group composition due to endogenous social interactions. This is achieved by identifying the social interactions parameter as the correlation between group composition and individual outcome that is specific to the extended benefits program.

This identification strategy is persuasive only if the REBP is a quasi-experiment. The paper discusses the two most important caveats regarding this assumption. First, the regions selected for REBP entitlement are not a random sample but rather they are characterized by a dominant steel sector. This is due to the fact that Austria's nationalized steel sector was facing severe problems in the late 1970s and throughout the 1980s. However, the fact that the REBP was strongly targeted to the steel sector also implies the existence of a sector that may not be affected by a region-specific shock. Indeed, whereas there clearly is a region-specific shock to employment in the steel sector, relative employment in the non-steel sector remains stable throughout the 1980s and 1990s. Second, it can be argued that even if the non-steel sector remained unaffected by a region-specific shock, firms and workers may have taken advantage of the generous benefit system in REBP regions in ways that can not be approximated by information on non-REBP regions. The paper shows that whereas the REBP affects the composition of the inflow into unemployment also in some non-steel industries, the inflow from the largest non-steel industry - the construction industry - is not affected by REBP. These two

\footnotetext{
${ }^{2}$ See Manski $(1993 ; 2000)$ for a discussion on identification of social interactions in linear models, and Brock and Durlauf (2001) for identification in non-linear models.
} 
pieces of evidence suggest that the REBP constitutes a quasi-experiment affecting a dominant share of unemployment spells.

There is a growing body of literature that studies the role of social interactions in outcomes that are predominantly determined at the individual level. First, the "canonical approach" is based on individual data and involves regressing an outcome on the group average of this outcome. This approach is criticized in Manski (1993) for failure to identify social interaction parameters but a number of solutions of the identification problem have been discussed. Case and Katz (1991) use instrumental variables to study neighborhood effects in the Boston area, Bertrand, Luttmer and Mullainathan (2000) identify network effects as the correlation between individual outcomes and group outcomes that is specific to a tightly defined reference group, and Duflo and Saez (2003) study the role of information and social interactions in retirement plan decisions in a field experiment. A second approach studies social interactions within groups that are formed at random (Sacerdote 2001) or individuals are induced to change group membership randomly (Katz, Kling and Liebman 2001). The third approach directly links spatial variance in crime rates (Glaeser et al. 1996) or unemployment rates (Topa 2001, Topa and Conley 2002) to social interactions. Finally, a fourth approach measures social interactions in laboratory experiments (Falk and Fischbacher 2002).

The main contribution of this paper is that it discusses the relevance of social interactions based on an actual change in labor market policy that affects an entire economy. This implies that the results of the analysis can be applied to labor market policy more readily than studies that are based on smaller scale field studies. Moreover, focusing on an actual policy change allows discussing the interplay between economic policy and social interactions. For instance, this paper shows that social interactions are about as important as the direct effect of REBP on individuals. Such information is important in discussing the potential response to programs which are targeted to specific individuals as opposed to programs that are targeted to entire groups of individuals. The second contribution of this paper consists in focusing on the relevance of social interactions in a market setting. Whereas previous research has focused predominantly on social pathologies such as crime or welfare dependence which are determined at the individual level, the aim of this paper is to assess whether such interactions are important in the determination of the equilibrium allocation of labor. This is important because it is not clear that social interactions are likely to be important in a market environment. Whereas it is straightforward that, for instance, the desire to conform to group behavior can be important in shaping outcomes that are determined outside of markets, it is not clear how such a desire translates to variance in market outcomes. For instance, competition among job seekers is expected to limit the extent to which the desire to conform to a norm of long-term 
unemployment is transmitted to market outcomes. The third contribution of this paper is that identification is based on a partial-population intervention. This approach allows studying interactions between groups and individuals without changing group membership. Thus, it is possible to separate the effect on the individual from changes in group behavior from the effect on the individual of changes of the environment or context. Moreover, studying interactions in existing groups is important in order to assess the actual strength of social interactions.

The paper is organized as follows. The following section gives the background on the Austrian unemployment insurance and the regional extended benefits program. Section 3 provides information on the data, on the sample selection procedure, and the definition of the reference group. Section 4 discusses identification of social interactions based on a partialpopulation intervention. Section 5 reports the analysis of the relevance of social interactions in labor supply, and section 6 concludes.

\section{Austrian Unemployment Insurance and the REBP}

The Unemployment Insurance System Individuals flowing out of employment have to register in person at the regional public employment service in order to be eligible for unemployment benefits. Individuals are entitled to unemployment benefits provided they are looking for work. Voluntary quitters and workers discharged for misconduct can not claim benefits until a waiting period of 4 weeks has passed. UB recipients are expected to search actively for a new job that should be within the scope of the claimant's qualifications, at least during the first months of the unemployment spell. Non-compliance with the eligibility rules is subject to benefit sanctions that can lead to the withdrawal of benefits for up to 4 weeks. In order to monitor the job search effort, caseworkers can demand that the unemployed report at the PES as often as once per week.

Compared to other European countries, the replacement ratio (UB relative to gross monthly earnings) is rather low. The amount of UB payments depends on previous earnings and, in 1990, the replacement ratio was $40.4 \%$ for the median income earner; $48.2 \%$ for a low-wage worker who earned half the median; and $29.6 \%$ for a high-wage worker earning twice the median. On top, family allowances are paid. UB payments are not taxed and not meanstested. There is no experience rating.

In the 1980s the duration of regular unemployment benefits was solely dependent on the duration of employment prior to registering at the public employment service. Individuals with no previous work experience were eligible for 12 weeks, individuals with 1 year out of the previous two years in employment were eligible for 20 weeks, and individuals with 3 years out of the previous 5 in employment were eligible for 30 weeks of regular unemployment benefits. 
In August 1989, the maximum duration of unemployment benefits was increased to 39 weeks for individuals aged 40-49 with 6 out of the previous 10 years in employment, and to 52 weeks for individuals aged 50 years or older who had spent 9 out of the previous 15 years in unemployment. ${ }^{3}$

After UB payments have been exhausted, job seekers can apply for 'transfer payments for those in need' ("Notstandshilfe"). As the name indicates, these transfers are means-tested and the job seeker is considered eligible only if she or he is in trouble. These payments depend on the income and wealth situation of other family members and close relatives and may, in principle, last for an indefinite time period. These transfers are granted for successive periods of 39 weeks after which eligibility requirements are recurrently checked. These post-UB transfers are lower than UB and can at most be $92 \%$ of UB. In 1990, the median post-UB transfer payment was about $70 \%$ of the median UB. Note however, that individuals who are eligible for such transfers may not be comparable to individuals who collect UB because not all individuals who exhaust UB pass the means test. The majority of the unemployed (59\%) received UB whereas $26 \%$ received post-UB transfers. In sum, the Austrian unemployment insurance system is less generous than many other continental European systems and closer to the U.S. system (Nickell and Layard, 1999). ${ }^{4}$

Restructuring of the Austrian steel industry and the REBP To protect its assets after World War II from Soviet appropriation and to provide the capital needed for reconstruction, Austria nationalized its iron, steel, and oil industries, large segments of the heavy engineering and electrical industries, most of the coal mines, and the nonferrous metals industries. Firms in the steel sector were part of a large holding company, the Oesterreichische Industrie AG, OeIAG. By the mid-1970s this holding company was running into serious problems related to shrinking markets, overstaffing, too heavy concentration on outmoded smokestack industries, insufficient research and development, and low productivity. Initially, the Austrian government covered the losses by subsidies. But in 1986, after the steel industry was hit by an oil speculation scandal and failure of a U.S. steel plant project, this protectionist policy was abolished. A new management was appointed and a strict restructuring plan was implemented. This plan aimed

\footnotetext{
${ }^{3}$ The empirical analysis in section 5 controls for this policy change by means of a dummy variable 'change in August 1989' taking the value 1 if the spell starts after August 1, 1989 (and the spell is not entitled to REBP), and 0 otherwise. Note, however, that it is not possible to identify the causal effect of this policy change on the duration of unemployment spells since there is no control group.

${ }^{4}$ It is interesting to note that the incidence of long-term unemployment in Austria is closer to U.S. figures than to those of other European countries. In 1995, when our sample period ends, $17.4 \%$ of the unemployment stock were spells with an elapsed duration of 12 months or more. This compares to $9.7 \%$ for the U.S. and to $45.6 \%$ for France, $48.3 \%$ for Germany, and $62.7 \%$ for Italy (OECD, 1995).
} 
at focusing on the holdings' core competencies. The result were layoffs due to plant closures and downsizing, particularly in the steel industry.

To mitigate the labor market problems in the concerned regions the Austrian government enacted a law that extended UB-entitlement to 209 weeks for a specific subgroup. An unemployed worker became eligible to 209 weeks of UB if he or she satisfied, at the beginning of his or her unemployment spell, each of the following criteria: (i) age 50 or older; (ii) a continuous work history (at last 15 out of the 25 years prior to the current unemployment spell in employment); (iii) location of residence in one of 28 selected labor market districts since at least 6 months prior to the claim; and (iv) start of a new unemployment spell after June 1988 or spell in progress in June 1988. The main Austrian newspapers discussed the possibility of such a selective change in the potential duration of unemployment benefits in February 1988. In April 1988, the parliament decided that REBP will be implemented. This decision was publicly announced at a press conference. However, at that time it was not yet clear which regions would benefit from REBP. The definite selection of the regions was completed in May 1988.

The REBP was in effect until December 1991 when a reform of these rules took place which came into effect in January 1992. The 1991-reform enacted two important changes. First, the reform abolished the benefit extension in 6 of the originally 28 regions. Second, the 1991-reform tightened eligibility criteria to extended benefits: new beneficiaries had to be not only residents, but also previously employed in a treated region. The program was abolished in August 1993.

Figure 1 shows the growth rate of real GDP in the period between 1980 and 1998. Except for 1981 and 1984, the business cycle conditions were relatively good in the period before REBP was introduced and in the pre-reform period. In the period after REBP was reformed, economic growth deteriorated, and in 1993, the year when REBP was abolished, there was a strong recession. Starting in 1994 the Austrian economy recovered and reached about the same growth rate as just before the REBP. Thus, in contrast to expectations, the program was not introduced to protect older workers in a period of problematic labor market conditions.

Figure 1

Figure 2 shows employment in treated regions divided by employment in control regions for the age group 40-44 in the period between 1980 until 1998 for the steel sector and for the non-steel sector. The figure concentrates on the age group 40-44 because this age group is in a similar labor market position as the age group 45-54. Furthermore, it is neither directly affected by the REBP nor are spillovers due to social interactions likely to be relevant 5 years below the age threshold. Employment in the steel sector is 3 times as large in treated regions 
than in control regions in the early 1980s. In comparison, relative employment is roughly .43 in 1991. This suggests that REBP is very strongly targeted to regions with a dominant steel sector. The figure also shows that there is a strong region specific shock to employment in the steel sector in treated regions. Starting in 1986, relative employment declines from a level of roughly 3 to a level of roughly 1.5 in 1991 and remains on that level. On the other hand, employment in the remaining sectors does not appear to be affected by a region specific shock. Relative employment in the non-steel sector is roughly constant at a level of slightly less than .3 in the period between 1980 and 1998. Thus, whereas the program can be understood to have alleviated labor market problems in the steel sector in treated regions, there is no evidence of a region specific shock to employment in other sectors. The evidence in figure 2 suggests that it may be possible to rely on individuals from the non-steel sector to study social interactions.

Figure 2

\section{Data and Definition of Group}

Data and Sample Selection To assess the relevance of social interactions in unemployment the empirical analysis is based on longitudinal individual data from two different sources: (i) the Austrian social security database which contains detailed information on the individuals' employment, unemployment and earnings history since the year 1972, and some information on the employer like region and industry affiliation; and (ii) the Austrian unemployment register that contains information on socio-economic characteristics. The data cover the universe of the unemployment inflow over the period June 16, 1986 to December 31, $1991 .^{5}$

The analysis concentrates on male workers aged 48-51 at the beginning of their spell who held a job prior to unemployment in a non-steel firm with a least 10 employees, and who either live and previously worked in a treated region (TR) or live and previously worked in region that is not entitled to REBP (control region; CR). Selecting a narrow age range has two advantages. First, it is reasonable to assume that (non-eligible) workers aged 48-49 are close substitutes to (eligible) workers aged 50-51 in employment. Second, it can be argued that individuals in the age bracket 48-51 are likely to be in the same reference group. The analysis focuses on individuals from non-steel firms due to the known endogeneity of REBP in the steel sector. Moreover, the sample is restricted to firms with at least 10 employees in order to reduce

\footnotetext{
${ }^{5}$ Recall that the program was abolished during the strong 1993 recession. This complicates the identification strategy because agents in treated regions may have taken advantage of the program in ways that are not recoverable from information on non-treated regions. In contrast, the pre-program and pre-reform period that we analyze are characterized by an expanding economy.
} 
the noise in constructing the reference groups. The main reason for excluding the individuals living in TRs who worked in a CR firm is that these individuals may have relocated prior to the unemployment spell in order to gain eligibility to the program. We exclude the individuals in the opposite working situation, living in CRs who worked in a TR firm, in order to reduce the potential classification errors when constructing the group indicators. There are two reasons for excluding women. The first reason is access to early retirement. Old age insurance rules allow women to retire already at age 55 , whereas the early retirement age for men is $60{ }^{6}$ Hence for eligible women the REBP provided a smooth transition to early retirement. The second reason why women were excluded from the analysis is that one eligibility criterion is a continuous work history (employment in 15 out of the last 25 years). As we can trace back employment histories only until 1972, classification errors are more likely for women than for men.

To avoid such classification errors for the remaining male sample we include only those males with a 'continuous' work history since 1972. A continuous work history is defined as a career with a ratio of actual to potential work experience since the year 1972 of at least 0.7. This ensures that only workers who satisfy the work experience requirement with a very high probability are included in the sample. Recall that eligibility requires 780 employment weeks (15 years) within the last 25 years, that is an actual-to-potential experience ratio of at least 0.6. Since we do not observe the entire 25 years-period prior to the spell, we use the more conservative criterion 0.7 to avoid misclassification.

Between July 1, 1986 and December 31, 1991, in total 95,389 males in the age group 48-51 entered unemployment from a regular job. We excluded those 21,735 spells by males who did not satisfy the work-experience requirement, 7,260 spells from the steel sector, 14,759 spells from firms with less than 10 employees in the month prior to inflow, 6,791 observations with residence in $\mathrm{TR}$ and previous employment in $\mathrm{CR}$ (or vice versa), 3,149 observations with missing information on the location of the previous employer, 2,023 observations with missing information on the regressor variables, and 4,303 spells with an empty reference group (as defined in the following subsection). The final sample comprises 35,369 unemployment spells; 16,890 spells in the age group 50-51, and 18,479 in the age group 48-49.

Definition of reference group There is a substantial body of literature in sociology regarding social networks in the labor market (Corcoran et al., 1980; Granovetter, 1995). Individuals care about the actions of family members, close friends, relatives, and workplace colleagues. Also, individuals tend to care about the actions of other individuals that are similar to them

\footnotetext{
${ }^{6}$ Access to early retirement is possible either if the individual has had a long spell of unemployment and/or has paid social security contributions for at least 35 years.
} 
with respect to age, and occupation. Arguably, in the domain of unemployment, the relevant reference group comprises former workplace colleagues. These individuals are likely to be similar with respect to occupation and job skills. Former workplace colleagues are also unemployed and thus in a position that is very similar to that of a particular individual. Moreover, social interactions are identified in the partial-population intervention approach based on variation in the reference group's entitlement to the program. The main source of such variation is the unemployed part of the reference group.

The reference group of an individual encompasses all other individuals in the age bracket 45-54 entering unemployment from the same previous employer as the individual in the year that is centered on the inflow date of the individual. ${ }^{7}$

Figure 3 illustrates this definition of the reference group. First, the date when individual i registers at the public employment service is recorded. Then, all unemployment spells originating from the same previous employer by other individuals in the age group 45-54 in a period not exceeding 182 days before or after individual i registers at the public employment service are selected. Thus, spells A and B are allocated to the reference group, whereas spell C is not because it does not start within the 182 days window since individual i has registered at the public employment service.

\section{Figure 3}

This definition of the reference group considers three important issues. First, seasonality in the inflow into unemployment does not affect the composition of the group in an important manner. For instance, suppose that firms tend to lay off older individuals in a different season than younger individuals. Choosing an inflow window of less than one year would generate variation in the proportion aged 50 or older in the reference group that reflects predominantly these firms' layoff policies. Second, the inflow window is symmetric in order to allow for social interactions both, between individuals who enter unemployment before and after person i does. Third, by focusing on the inflow dates, this definition of the reference group does not rely on the realization of the duration of unemployment in the reference group. This is advantageous because previous research emphasizes that the correlation between individual outcomes and group outcomes does not provide information on social interactions.

Group Indicators Based on the above definition of the reference group two indicators at the group level were calculated for each unemployment spell: (i) the proportion in the group aged 50 to $54 A_{(-i) g_{i}}$, and (ii) the proportion in the group satisfying all eligibility criteria

\footnotetext{
${ }^{7}$ The paper uses the terms 'individual' and 'spell' interchangeably. The unit of analysis is, however, the unemployment spell.
} 
$R_{(-i) g_{i}}$. Specifically, let $t_{i}$ denote the inflow date of spell $i$ in days since a reference date. Let $e_{i}$ denote the identification number of the previous employer of spell $i$. The reference group of spell $i$ is the set of spells $G_{i} \equiv\left\{j\left|e_{i}=e_{j}, 45 \leq a g e_{j}<55,\right| t_{i}-t_{j} \mid \leq 182, i \neq j\right\}$. Then,

$$
A_{(-i) g_{i}} \equiv \frac{\sum_{j=1}^{N} A_{j} I\left(j \in G_{i}\right)}{\sum_{j=1}^{N} I\left(j \in G_{i}\right)}
$$

with $A_{j}=1$ if spell $j$ is in the age group 50 to 54 , and $A_{j}=0$ otherwise, and $N$ representing the number of spells in the age group 45 to 54 . The indicator $A_{(-i) g_{i}}$ is useful because it is strongly correlated with $R_{(-i) g_{i}}$ but does not reflect the distance to the border of treated regions. Moreover, this indicator allows implementing an informal test regarding the identifying assumption discussed in the following section.

Defining $W_{j}=1$ if the spell $j$ satisfies the previous work criterion, and $W_{j}=0$ otherwise, and $T_{j}=1$ if the location of residence of spell $j$ is in the original 28 treated regions, and $T_{j}=0$ otherwise

$$
\begin{aligned}
& R_{(-i) g_{i}} \equiv \frac{\sum_{j=1}^{N} A_{j} W_{j} T_{j} I\left(j \in G_{i}\right)}{\sum_{j=1}^{N} I\left(j \in G_{i}\right)} \text { if } T_{i}=1 \\
& R_{(-i) g_{i}} \equiv \frac{\sum_{j=1}^{N} A_{j} W_{j}\left(1-T_{j}\right) I\left(j \in G_{i}\right)}{\sum_{j=1}^{N} I\left(j \in G_{i}\right)} \text { if } T_{i}=0
\end{aligned}
$$

The indicator $R_{(-i) g_{i}}$ distinguishes between individuals who are resident in TRs, and individuals who are resident in CRs in order to reflect for both groups the proportion of individuals satisfying the age and work criterion living in the same region. Note that $R_{(-i) g_{i}}$ does not reflect the timing of the program. This information is added to $R_{(-i) g_{i}}$ when it is interacted with the during program dummy $D_{i}=1$ if the spell starts after June 1988, and $D_{i}=0$ otherwise. Section 5 contains a sensitivity analysis that discusses this issue.

The average reference group consists of 25 individuals (Table A1). The proportion aged 50 to 54 in the average reference group is $45 \%$, and roughly $34 \%$ of the members of each reference group satisfy the age, work, and residence criteria.

\section{Identification}

This section discusses identification of social interactions with a selective partial-population intervention in a differences-in-differences setting.

Let $y$ denote the outcome, i.e. the duration of unemployment, the duration of unemployment covered by unemployment insurance or the probability that the unemployment spell 
exceeds a certain amount of time. Let $g$ indicate the attributes of the reference group, and let $R$ denote the fact that the individual is aged 50 or older and has a continuous work history. ${ }^{8}$ Then, consider the linear ${ }^{9}$ model of social interactions in the population in a situation without the extended benefits program

$$
y=\beta_{0}+\beta_{1} E(y \mid g)+\beta_{2} R+\beta_{3} E(R \mid g)+g^{\prime} \delta+\varepsilon
$$

where $\beta_{1} \neq 0$ indicates that individuals tend to be unemployed longer in groups with long unemployment duration (endogenous social interactions), $\beta_{3} \neq 0$ reflects the fact that unemployment duration may be affected composition of the reference group with respect to age or work experience (exogenous or contextual interactions), and $\delta \neq 0$ suggests that unemployment spells may be similar in groups starting from the same previous employer (correlated interactions). The parameter $\beta_{2}$ measures ex-ante differences in duration between eligible and non-eligible spells. Manski (1993) shows that endogenous social interactions are not identified in this linear model because the expectation of the group's outcome, $E(y \mid g)$, depends linearly on the group's average exogenous characteristics, $E(R \mid g)$, and on the group's attributes $g$. Provided that $\beta_{1}<1$, the reduced form for $y$ is

$$
y=\frac{\beta_{0}}{1-\beta_{1}}+\underbrace{\frac{\left(\beta_{2} \beta_{1}+\beta_{3}\right)}{1-\beta_{1}}}_{\lambda} E(R \mid g)+\beta_{2} R+g^{\prime} \frac{\delta}{1-\beta_{1}}+\varepsilon
$$

This shows that endogenous social interactions are not identified because there is only information on two parameters $\lambda$ and $\beta_{2}$ whereas we need information on three parameters in order to infer $\beta_{1}$. Intuitively, there are two distinct reasons why the outcome variably $y$ is correlated with the group's age and experience structure. First, such a correlation arises due to contextual interactions. Second, such a correlation arises due to the direct effect of being aged 50 or older and having long previous work experience on long-term unemployment affecting each individual within the group. This direct effect changes the expectation of the outcome within the group and thus, there is a second, indirect change in the individual outcome. The main difference between these two channels is that the former operates even if endogenous social interactions are irrelevant whereas the latter channel disappears.

The main idea in applying the policy change to identify social interactions is that the program allows investigating the strength of the second channel. Introducing the program creates an incentive for eligible individuals to reduce job search intensity and to increase the

\footnotetext{
${ }^{8}$ This section abstracts from additional exogenous characteristics in order to simplify the discussion. Note that the empirical analysis controls for a number of additional characteristics (section 5).

${ }^{9}$ Brock and Durlauf (2001) discuss identification of social interactions in nonlinear models.
} 
reservation wage. If social interactions are relevant in labor supply decisions, this will affect the magnitude of the reduced form parameter because the policy change increases $\beta_{2}$. If social interactions are unimportant, the reduced form parameter merely captures exogenous social interactions. Specifically, the reduced form model with policy is given by

$$
y=\frac{\beta_{0}}{1-\beta_{1}}+\underbrace{\frac{\left(\beta_{2}^{R} \beta_{1}+\beta_{3}\right)}{1-\beta_{1}}}_{\lambda^{R}} E(R \mid g)+\beta_{2}^{R} R+g^{\prime} \frac{\delta}{1-\beta_{1}}+\varepsilon
$$

where $\beta_{2}^{R}$ exceeds $\beta_{2} \cdot{ }^{10}$ Consider the change in the reduced form parameter $\lambda^{R}-\lambda=$ $\frac{\left(\beta_{2}^{R} \beta_{1}+\beta_{3}\right)}{1-\beta_{1}}-\frac{\left(\beta_{2} \beta_{1}+\beta_{3}\right)}{1-\beta_{1}}=\frac{\beta_{1}}{1-\beta_{1}}\left(\beta_{2}^{R}-\beta_{2}\right)$. Second, the direct effect of extended benefits, $\beta_{2}^{R}-\beta_{2}$, is identified by comparing the corresponding parameters in the model without and with policy. Thus, estimates of the change in the parameter attached to the group's share satisfying the REBP criteria and the change in the parameter attached to the individual benefit eligibility status identify the structural social interactions parameter $\beta_{1}$.

It is possible to rely on the information on regions that were never eligible to the program to control for economy wide changes over time in the reduced form parameters. Recall that $D_{i}=1$ if a spell starts in or after June 1988, $T_{i}=1$ if the location of residence is in the 28 treated regions, and $A_{i}=1$ the individual is aged 50 or older at the beginning of the unemployment spell. The empirical implementation of this difference-in-difference identification strategy is given by

$$
\begin{aligned}
y_{i}= & \lambda_{0} R_{(-i) g_{i}}+\lambda_{1} D_{i} R_{(-i) g_{i}}+\lambda_{2} T_{i} R_{(-i) g_{i}}+\lambda_{3} D_{i} T_{i} R_{(-i) g_{i}}+ \\
& \lambda_{4} A_{i}+\lambda_{5} D_{i} A_{i}+\lambda_{6} T_{i} A_{i}+\lambda_{7} D_{i} T_{i} A_{i}+ \\
& \lambda_{8}+\lambda_{9} D_{i}+\lambda_{10} T_{i}+\lambda_{11} D_{i} T_{i}+g_{i}^{\prime} \delta+\epsilon_{i}
\end{aligned}
$$

with $\lambda_{3}$ measuring the program specific change in the reduced form parameter that captures the correlation between the individual outcome with the group's share satisfying REBP criteria $R_{(-i) g_{i}}$, and $\lambda_{7}$ capturing the program specific change in the outcome for individuals who are entitled to REBP.

\footnotetext{
${ }^{10}$ Theoretically, the net effect of increases in benefit duration on unemployment duration is not clear. See Mortensen (1977) for an early model of job search or Van den Berg (1990) for a more recent discussion of the effect of benefit duration on unemployment duration. Applied studies, however, find a significant and positive effect of extended benefits on unemployment duration. See Card and Levine (2001), Katz and Meyer (1990) for evaluations of the effects of prolonged unemployment benefits on unemployment duration in the U.S. or Lalive and Zweimüller (2002) for an evaluation of this effect in Austria.
} 
In addition to the linear model, the identifying assumptions are that both, the structural social interactions parameter and the parameter capturing exogenous social interactions remain unaffected by the program, i.e.

$$
\begin{aligned}
& \beta_{1}^{R}=\beta_{1} \\
& \beta_{3}^{R}=\beta_{3}
\end{aligned}
$$

Arguably, the assumption regarding the structural social interactions parameter is innocuous. This parameter reflects the strength of social networks among the unemployed. It is difficult to see how the introduction of the program may have altered these networks.

The crucial identifying assumption refers to the absence of program-specific changes in contextual interactions. At first, this assumption appears to be innocuous. The main aggregate statistic affecting the probability of leaving unemployment is labor market tightness - the ratio of vacancies to job seekers. As long as inference is conditional on a statistic summarizing the state of the labor market, there is no reason why the composition of the reference group should affect individual exit from unemployment. ${ }^{11}$ Nevertheless, we address the possibility of changes in the parameter reflecting contextual interactions in two indirect ways. First, it is plausible that individuals satisfying the previous work requirement are substitutes around the age threshold without the program. Thus, before the program was introduced, the correlation between the individual outcome with the main regressor $R_{(-i) g_{i}}$ is likely to be similar around the age threshold. However, note that the program introduces a strong distinction at the age threshold 50. Eligibility increases the bargaining power of the workers above the threshold strongly while leaving unaffected the bargaining power of the younger workers. Also, $R_{(-i) g_{i}}$ reflects the share of individuals with strong bargaining power within the reference group. Thus, if contextual interactions are relevant, they are likely to change strongly when moving across the threshold because the bargaining position of the individual changes strongly. This motivates identifying the reduced form parameter $\lambda_{3}$ separately ${ }^{12}$, in the sample covering spells aged 50-51 $\left(A_{i}=1\right)$ and in the sample consisting of spells aged 48-49 $\left(A_{i}=0\right)$ as follows

$$
\begin{aligned}
y_{i}= & \lambda_{0} R_{(-i) g_{i}}+\lambda_{1} D_{i} R_{(-i) g_{i}}+\lambda_{2} T_{i} R_{(-i) g_{i}}+\lambda_{3} D_{i} T_{i} R_{(-i) g_{i}}+ \\
& \lambda_{8}+\lambda_{9} D_{i}+\lambda_{10} T_{i}+\lambda_{11} D_{i} T_{i}+g_{i}^{\prime} \delta+\epsilon_{i}
\end{aligned}
$$

\footnotetext{
${ }^{11}$ Because reliable data on vacancies is not available, the empirical analysis controls for the state of the labor market via the unemployment rate in the age group 45-54.

${ }^{12}$ Identifying the causal parameter in distinct ways in the context of quasi-experiments is recommended by Meyer (1995).
} 
Again, the parameter $\lambda_{3}$ captures the change in the correlation between $y_{i}$ and $R_{(-i) g_{i}}$ that is specific to the program implementation. This change should be identical in the non-entitled as in the entitled sample if it is due to social interactions. ${ }^{13}$

The second way of addressing changes in contextual interactions tests whether there is a program specific change in the correlation between the individual outcome with a second regressor defined at the group level that does not capture the group's share satisfying REBP criteria. Let $X_{(-i) g_{i}}=A_{(-i) g_{i}}-R_{(-i) g_{i}}$ capture the share satisfying the age criterion but not the previous work or location of residence criteria. The second test consists of introducing $X_{(-i) g_{i}}$ along with all interactions with $D_{i}$ and $T_{i}$ to the difference-in-difference regression (5). There should be no region-specific change in the effect of this variable on the outcome because $X_{(-i) g_{i}}$ measures the share of spells in the reference group that are not entitled to REBP because they violate either the previous work or the residence criteria. The important advantage of such a test is that it adds plausibility to the identifying assumption relating to the main regressor $R_{(-i) g_{i}}$. It is unlikely that contextual or correlated effects change in a manner that is orthogonal to $X_{(-i) g_{i}}$ but correlated with $R_{(-i) g_{i}}$.

The remaining condition under which the identification strategy works deals with correlated interactions, i.e. the potential for omitted variables to bias the results. In the difference-indifference setting, the assumption under which correlated interactions are irrelevant is that the conditional expectation of the error term is not region and time-specific, i.e.

$$
\begin{aligned}
& E\left(\epsilon_{i} \mid g_{i}, R_{(-i) g_{i}}, D_{i} R_{(-i) g_{i}}, T_{i} R_{(-i) g_{i}}, D_{i}, T_{i}, D_{i} T_{i} R_{(-i) g_{i}}, D_{i} T_{i}\right) \\
= & E\left(\epsilon_{i} \mid g_{i}, R_{(-i) g_{i}}, D_{i} R_{(-i) g_{i}}, T_{i} R_{(-i) g_{i}}, D_{i}, T_{i}\right)
\end{aligned}
$$

Section 2 provides evidence that there was no region-specific shock to the level of employment in the non-steel sector (figure 2). However, it is possible that the REBP affected the composition of the inflow in such a way that inference on social interactions becomes impossible. Whereas it is not possible to assess the validity of (6) with respect to unobservable characteristics, the paper proposes to investigate whether the composition of the inflow is affected in a program-specific way along important observable characteristics (Share satisfying

\footnotetext{
${ }^{13} \mathrm{~A}$ second reason motivating the same separation of the sample is that the effects of this extended benefits policy may be heterogeneous. The degree to which individuals decide to reduce search effort and increase the reservation wage depends on variables that are not observed in the dataset such as household income. For individuals with a high household income, the REBP is a much more generous extension than for individuals with a low household income because the latter are eligible for up to $92 \%$ of previous unemployment benefits in the form of unemployment assistance. If these unobserved variables that determine the level of unemployment assistance transfers are correlated with $R_{(-i) g_{i}}$ the reduced form parameter reflects heterogenous treatment effects in addition to social interactions. Splitting the sample allows discussing the change in the social interactions parameter separately for the eligible spells as well as for the non-eligible spells.
} 
REBP criteria, earnings, firm size). This procedure is informative on the validity of (6) as long as there are no unobserved characteristics that are orthogonal to these important observable characteristics. We defer a detailed discussion of changes in the composition of the inflow to the following section (table 5).

\section{Results}

Descriptive Analysis Table 1 shows the risk of long-term unemployment, i.e. the share of spells that last longer than 6 months, by region of residence and REBP entitlement for the period before the program was introduced (column 'Before') and for the during period (column 'During'). Moreover, the analysis focuses on the event that the spell exceeds 6 months because this measure is not influenced by right censoring and is, arguably, an indicator that is more readily observed by individuals than mean unemployment duration. Long-term unemployment can be observed after 6 months whereas the mean duration in the group can potentially never be calculated exactly. Note, however, that results based on different outcome indicators are provided as a sensitivity analysis below.

In the period before REBP, the risk of long-term unemployment was roughly $9 \%$ for individuals satisfying all REBP criteria. The corresponding figure was slightly lower $(8.6 \%)$ for individuals aged 48-49 with residence in treated regions. The risk of the spell duration exceeding 6 months increases strongly in the period when REBP is introduced for the age group 50-51, from $9.0 \%$ to $16.7 \%$. There is a decrease in the risk of long-term unemployment in the age group 48-49 in treated regions, from $8.6 \%$ to $6.6 \%$. This evidence is consistent with the hypothesis that job seekers below the age of 50 years in treated regions may have found jobs more quickly because the program reduced job search incentives for individuals aged 50 or older. Thus, the risk of long-term unemployment increased by 9.6 percentage points more strongly for the entitled individuals than for the non-entitled individuals, in treated regions.

Table 1

The lower panel in table 1 shows the corresponding calculations for the set of regions without REBP entitlement. This allows discussing whether there was an age specific secular trend in the risk of long-term unemployment in the period when REBP was introduced. Indeed, the risk of long-term unemployment increases slightly more in the age group 50-51 than in the age group 48-49, but this increase is very small and insignificant. Nevertheless, subtracting this secular trend from the effect reported above reveals that the risk of long-term unemployment increased by 8.8 percentage points more strongly for the entitled individuals than would be expected given the information on non-entitled individuals in treated and control regions. 
Table 2 investigates how the risk of long-term unemployment may be affected by social interactions by allocating each spell to one two groups. The first group contains all spells with a reference group containing "many old former workplace colleagues", that is, spells with a share of spells in the age group 50-54 exceeding .5. The second group contains spells with "few old former workplace colleagues". Additionally, the calculations are performed separately for the age group 50-51 and the age group 48-49 in order to condition on REBP eligibility. Table 2 shows that the probability of long-term unemployment increases very strongly, from $7.8 \%$ to $20.9 \%$, in the age group 50-51 with "many old colleagues". There is a substantially weaker increase in the risk of long-term unemployment for spells with "few old colleagues", from 9.8 $\%$ to $11.5 \%$. Thus, the probability of long-unemployment spells increases by 11.4 percentage points stronger for the entitled individuals with many old former workplace colleagues. The corresponding calculation in the control regions shows that the risk of long-term unemployment increases slightly more strongly in the group with "many old former workplace colleagues". The difference-in-difference calculation shows thus that the risk of long-term unemployment increases by 9.6 percentage points more strongly for the entitled individuals with "many old workplace" colleagues.

Table 2

Moreover, calculations for the age group 48-49 provide evidence of a spillover effect of REBP on labor supply decisions. Table 4, right panel, shows that there is an increase in the risk of long-term unemployment from $4.9 \%$ to $7.5 \%$ for spells in the age group $48-49$, living in treated regions with a high proportion of individuals aged 50 or older in the reference group. There is a strong decrease in the risk of long-term unemployment, from $10.8 \%$ to $5.7 \%$, for spells with "few old former workplace colleagues" leading to a relative increase in the risk of long-term unemployment in the group with "many old former workplace colleagues". The corresponding calculations in the control regions suggest that the risk of long-term unemployment increases only slightly more strongly for spells with "many old former workplace colleagues". Thus, the risk of long-term unemployment increases disproportionately, by 7.1 percentage points, in a group that does not satisfy the age eligibility criterion but has, arguably, strong social contacts with entitled individuals.

Regression Analysis In order to assess social interactions in a multivariate setting, the linear probability model is applied to the outcome variable $y_{i}=1$ if the spell lasts longer than 6 months, and $y_{i}=0$ otherwise. There are mainly two arguments for the linear probability model. First, the strength of the "partial-population intervention" is that social interactions are identified in a linear model. Introducing non-linearity at this stage is thus not necessary 
for identification. Moreover, Moffitt (1999) argues that in applications with main focus on the marginal effects it may be useful to consider the linear probability model. Nevertheless, we also investigate results based on the logit model in the sensitivity analysis below. Reported asymptotic z-Values correct for heteroskedasticity using White (1980)'s method. Furthermore, to avoid the Moulton (1990) pitfall when regressing an aggregate variable on an individual outcome, the error term is allowed to be correlated cells defined by the previous employer.

Table 3 performs essentially the same difference-in-difference calculation as table 2 additionally controlling for a number of individual, firm, and region characteristics. Individual characteristics are age, marital status, education, white collar job, nationality, work experience in the previous 10 years, and $\log$ (average daily earnings in the previous job), i.e. earnings in a year divided by number of days worked in that year. The firm characteristics are the log of, respectively, the number of individuals in the reference group, firm size, average earnings, and the percentage of workers in the age group 50-54 relative to workers in the age group 45-54. Firm size, average earnings and the percentage of workers in the age group 50-54 are measured on the 10th day of the month preceding individual i's inflow month. Regional characteristics are the unemployment rate in the age group 45-54 in the region of residence, and a variable capturing the distance from the individual's residence to the border between treated and control regions. Table A1 provides descriptive statistics on these variables.

\section{Table 3}

The results in the left panel of table 3 show that there is no ex ante correlation between the share aged 50-54 in the reference group and the probability of long term unemployment. Also, there are no differences in this correlation between spells with residence in treated regions compared to spells with residence in control regions. Also, there is a statistically significant but quantitatively unimportant change in this correlation as of June 1988 (coefficient 'During * Share aged 50-54'). Since the variable share aged 50-54 is standardized, the estimates suggest that the probability of long-term unemployment is higher by 1 percentage point for spells with a one standard deviation (.265) higher share of spells in the age group 50-54. The most important change in the correlation between the outcome and group composition occurs, however, in treated regions after REBP was introduced. The estimates suggest that the risk of long-term unemployment increases by 4.5 percentage points due to an increase in the share aged 50-54 in the reference group.

Second, results in table 2 for the age group 48-49 also indicate that there is no a priori correlation between the age composition of the reference group and the probability of long-term unemployment. In contrast to the older age group, the probability of long term unemployment is estimated to be lower in treated regions the higher the share aged 50 and older in the reference 
group. Similar to previous results, there is a REBP-specific increase in the correlation between the outcome variable and group composition in the sample covering the age group 48-49.

The estimates also show the differences between spells in treated regions and spells in control regions both, before REBP and during REBP. In both age groups, there are no ex ante differences in the probability of long-term unemployment (coefficient 'Treated region'). In both age groups, there is a significant reduction in the probability of long-term unemployment over time (coefficient 'During'). This improvement in job chances can probably be explained by the period of positive growth of the Austrian economy. In the age group 50-51, there is a significant increase in the probability of long-term unemployment by 4 percentage points due to REBP (coefficient 'During * Treated regions') whereas there is a significant reduction in the probability of long-term unemployment for the age group 48-49 due to REBP. Taken together, the estimates suggest that the probability of long-term unemployment increased by 6.8 percentage points more strongly in the age group 50-51 relative to the age group 48-49 due to REBP.

Of course, the age composition of the reference group reflects only imperfectly the proportion in the reference group actually entitled to REBP. It is possible to investigate to what extent the changes observed in table 3 are actually due to the 'Share satisfying all REBP criteria'. Table 4 decomposes the effect of the regressor 'Share aged 50-54' into an effect due to 'Share satisfying REBP criteria' and into effect due to 'Rest', defined as the difference between 'Share aged 50-54' and 'Share satisfying REBP criteria'. The 'Rest' variable captures, thus, the share of spells within the reference group who do not satisfy either the previous work or the residence criterion. Thus, table 4 implements the test of the identifying assumption discussed in the previous section.

The results indicate that in the age group 50-51 the change in the correlation between the outcome and group composition is only due to the share of spells satisfying all REBP criteria. The estimates show that the probability of long-term unemployment is larger by 5.7 percentage points due to an increase in the share satisfying REBP criteria. There is no corresponding REBP specific change between the share also satisfying the age criterion but violating either the residence or previous work criterion (coefficient 'During * Treated region * Rest'). However, the estimates for the age group 48-49 show the opposite picture. Here, the change in the correlation between the outcome and group composition is only due to the 'Rest' variable capturing the share within the reference group aged 50 or older that is not entitled to REBP. This suggests that the identifying assumption regarding the 'Share satisfying REBP criteria' may be violated. In principle, these findings could be due to both, a program specific change in contextual interactions and due to program-specific changes in the composition of the inflow. 
It is possible to discuss program-specific changes in the relative size and the composition of the inflow in treated regions and control regions in order to discuss potential quantity and quality effects of REBP. Table 1 provides evidence on the relative size of the inflow. Whereas the inflow in the age group 48-49 in treated regions was roughly 28.3 percent $(=1447 / 5109)$ of the inflow in the same age group in control regions before REBP, this ratio dropped to 26.3 percent when REBP was introduced. In contrast, the relative inflow in the age group 50-51 increased from $28.9 \%$ to $30.7 \%$ due to REBP. This is strong evidence that workers in the age group 50-51 are more likely to have entered unemployment than workers in the age group 48-49.

Table 5 investigates the composition of the inflow with respect to the variable identifying social interaction effects - the share of spells satisfying REBP criteria in the reference group, $R_{(-i) g_{i}}$, earnings in previous job (in logs), actual work experience in the previous 10 years, marital status, and firm size (in logs). Daily earnings and work experience summarize past labor market success, firm size characterizes the previous firm, and marital status is a rough proxy for household income that is an important determinant of the REBP effect. The table reports the REBP specific change in the correlation of each variable with the Share satisfying REBP criteria (column 'A') and the change in the mean of the variable due to REBP (column 'B'). These coefficients are computed in regressing each variable on a set of three dummy variables 'During', 'Treated region', and 'During * Treated region' and all interaction terms between these dummies and the variable 'Share satisfying REBP criteria'. ${ }^{14}$

Table 5

Clearly, there is a significant and quantitatively strong increase in the non-steel inflow in terms of the variable 'Share satisfying REBP criteria'. In the age group 50-51, the share satisfying REBP criteria is roughly 5 percentage points higher than expected. In the age group 48-49 there is a smaller but statistically significant increase in the share satisfying the program criteria. Second, there is an increase in daily earnings by roughly 2.2 percentage points for spells in the age group 50-51 whereas there is a decrease by 3.5 percentage points for spells in the age group 48-49 that is specific to REBP. Perhaps more importantly, there is a REBP specific change in the correlation between the share satisfying program criteria and previous earnings in the age group 50-51. Workers in a reference group which has a one standard deviation

\footnotetext{
${ }^{14}$ The regression model for the all variables except the 'Share satisfying REBP criteria' is $y_{i}=\alpha_{0} R_{(-i) g_{i}}+$ $\alpha_{1} D_{i} R_{(-i) g_{i}}+\alpha_{2} T_{i} R_{(-i) g_{i}}+\alpha_{3} D_{i} T_{i} R_{(-i) g_{i}}+\alpha_{4}+\alpha_{5} D_{i}+\alpha_{6} T_{i}+\alpha_{7} D_{i} T_{i} .+\epsilon_{i} . \quad R_{(-i) g_{i}}$ is standardized, i.e. $R_{(-i) g_{i}}$ is expressed as deviation from the sample mean and divided by the sample standard deviation. The regression model for the 'Share satisfying REBP criteria' is $y_{i}=\alpha_{4}+\alpha_{5} D_{i}+\alpha_{6} T_{i}+\alpha_{7} D_{i} T_{i} .+\epsilon_{i}$. Column A in table 5 reports $\alpha_{3}$ and column $\mathrm{B}$ in table 5 reports $\alpha_{7}$.
} 
higher share of members satisfying REBP criteria are estimated to have earned roughly 9.2 $\log$ points more in the previous job. There is no corresponding REBP specific change in this correlation in the age group 48-49. Third, the REBP inflow in the age group 48-49 has .138 years lower work experience. There is a REBP specific change in the correlation between the share satisfying REBP criteria and work experience in the age group 50-51. Fourth, there is no change in either the mean proportion married nor in the correlation between marital status and the share with eligibility to REBP. Finally, there is a REBP specific increase in the average size of the previous employer (age group 50-51) as well as in the correlation between this variable and entitlement to REBP (both age groups). This means that the average spell in treated regions in the period when the REBP in force was significantly different from the inflow at other periods of time in the same regions, and in control regions. Moreover, the finding that a number of these variables are correlated with the 'Share satisfying REBP criteria' to a degree that can not be reconstructed from the non-affected regions casts strong doubts about the identifying assumption (6).

Table 5 also reports inflow effects separately, for the construction inflow and for the other non-steel inflow. This division of the sample is motivated by the fact that the construction inflow is roughly 60 percent of the entire non-steel inflow. This decomposition shows that the strong inflow effects discussed earlier are limited to the non-steel sector excluding construction. There are no program-specific changes regarding the composition of the inflow from the construction sector (with the exception of previous work experience in the age group 48-49). Furthermore, even though the relative inflow increases slightly in the period with REBP, both age groups are affected in exactly the same manner. ${ }^{15}$ The average observable quality of individuals is not correlated differently in treated regions in the period with REBP with the main regressor, the 'Share satisfying REBP criteria'. Moreover, it is likely that the evidence regarding observables is also valid for unobservables. The evidence in table 5 will only fail to detect differences in unobservables at the individual level if individuals differ along an unobservable dimension that is orthogonal to past earnings.

The evidence in table 5 motivates analyzing the inflow from the construction sector separately from the other non-steel sector. Table A1 provides descriptive statistics on the construction inflow and on the other non-steel inflow. In comparison with the non-steel inflow, the construction sector is characterized by smaller but less dispersed reference groups. Whereas the average reference group contains 31 spells in the other non-steel inflow sample (with standard deviation 92), the average reference group in the construction inflow contains 21 spells (with

\footnotetext{
${ }^{15}$ The finding of no inflow effects is not specific to the subset of variables chose here. In the construction sector we find no REBP specific change in the correlation between the share satisfying REBP criteria and any of the control variables listed in table A2 at the 5 percent level.
} 
standard deviation 36). There are neither important differences with respect to the proportion aged 50 to 54 nor with respect to the proportion satisfying REBP criteria. Table A1 also shows means and standard deviations on a number of characteristics of the previous employer. Construction firms are smaller, pay somewhat less than the average firm, and the proportion of workers aged 50-54 in the age bracket 45-54 is slightly higher in construction firms. There are fewer white collar workers in the construction inflow, and construction workers have about .44 years less actual work experience in the previous 10 years. There are no further important differences between the construction sector and the other non-steel inflow.

There are a number of reasons why the construction sector remains unaffected by REBP. First, employment in the construction sector is strongly seasonal. When firms in the construction sector lay off workers in December, managers expect to re-hire a substantial fraction of these workers in the spring. This implies that - in contrast to the remaining sector - it is less advantageous to concentrate layoffs on a particular age group. Furthermore, the Austrian economy was doing relatively well in the beginning of the REBP period (figure 1) and there was no region specific shock to the non-steel sector (figure 2). Thus, firms in the construction sector did not need to downsize in the period from 1986 until 1991.

Table 6 analyzes the relevance of social interactions in labor supply decisions separately, for the construction inflow and for the other non-steel inflow. Estimates for the construction inflow suggest that there is a statistically significant and quantitatively important increase in the risk of long term unemployment due to a change in the share satisfying REBP eligibility criteria, both in the entitled age group 50-51 and in the non-entitled age group 48-49. Moreover, the REBP specific change in the correlation between the outcome and the group's composition with respect to entitlement to the program is of roughly the same order of magnitude for spells who are actually entitled to REBP and also for spells who are not entitled to REBP. An increase by one standard deviation in the share satisfying REBP criteria is associated with an increase in the probability of long-term unemployment of between 3 to 4 percentage points. This suggests that there is no program-specific change in the importance of contextual interactions, i.e. $\beta_{3}$ is not program specific.

Table 6 also shows that there are no changes in the correlation between the outcome and the share of spells in the reference group aged 50 or older that violates either the previous work or the location of residence REBP criteria or both (coefficient 'During * Treated region * Rest'). This suggests that there were no further REBP specific changes affecting the correlation between individual outcomes and the reference group's composition.

\section{Table 6}

Results for the other non-steel inflow in the age group 50-51 also suggest that there is 
a REBP specific change in the correlation between the 'Share satisfying REBP criteria' and the probability of long-term unemployment. In contrast to the results for the construction sector, however, there is no evidence of such a change in the age group 48-49. Taken together, these results are consistent with the hypothesis that the regressor 'Share satisfying REBP criteria' reflects social interactions as well as potential age group specific changes in contextual interactions or unobserved individual characteristics.

Sensitivity Analyses Table 7 reports the estimated coefficient on the variable that captures social interactions ('During * Treated region * Others entitled') in a series of sensitivity analyses based on the construction inflow. Panel A studies whether potential anticipation effects may affect identification of social interactions. There are two important concerns with anticipation. The first concern holds that because the policy was publicly discussed as early as February 1988 there may have been reactions on the part of firms or workers that may affect identification of social interactions. This concern can be addressed, roughly, by assuming that REBP already starts as of February 27, 1988 - the day when the program was discussed in the national newspapers for the first time. Results show that the social interactions parameters are not sensitive to this modification of the timing of the program. This is probably due to the fact that the definite selection of the regions was only made public about one month before the program was actually implemented. The second concern with anticipation holds that the individuals in treated regions aged just below the age of 50 may be willing to accept any regular job as soon as they turn 50 because upon loosing this job they are in a system of very generous unemployment benefits. ${ }^{16}$ In order to discuss this issue, the sensitivity analysis disregards spells in the age group 49 in treated regions in the period when REBP was in force. In the age group 50-51 we exclude spells aged 51 in order to assess the sensitivity of the baseline result to age. Results indicate that there is a slight reduction in the social interactions parameter based on the age group below 50. However, there is a corresponding slight reduction in the age group aged 50 years or older. Moreover, the social interactions parameters are positive, significant, and quantitatively of the same order of magnitude as reported previously. This suggests that the anticipation effects are not relevant.

Table 7

Panel B discusses the concern that the 'Share satisfying REBP criteria' may reflect firms' decisions regarding re-hiring of the previously laid off workers. This concern can be addressed

\footnotetext{
${ }^{16}$ Note that the REBP entitlement rules are conditional upon the age at the start of the unemployment spell, so individuals do not automatically gain REBP entitlement as soon as they turn 50 .
} 
by investigating whether the estimate of the social interactions parameter is affected by the timing of inflow in the reference group. The idea is that, by construction, the inflow structure after spell i enters unemployment is more closely related to long-term unemployment than the inflow structure before spell i enters unemployment. If the 'Share satisfying REBP criteria' merely reflects labor demand effects, the observed change in the correlation between long-term unemployment and group composition will be stronger for a variable that captures the structure of the inflow after spell i enters unemployment. The sensitivity analysis tests this hypothesis by allowing for separate coefficients for the number of spells satisfying REBP criteria entering before and after spell i expressed as a proportion of the total number of spells in the reference group. The results indicate that inflow composition prior to the inflow date of spell $i$ as well as inflow composition after the inflow date of spell i are equally important in identifying the social interactions parameter. This evidence is inconsistent with the interpretation that the 'Share satisfying REBP criteria' primarily reflects the effect of firms' decisions on the probability of long-term unemployment.

Panel $\mathrm{C}$ addresses potential measurement concerns with the analysis. The first row checks whether unobserved region specific characteristics affect identification of the social interactions parameter. This can be investigated by adding a set of region effects which are interacted with the 'During' program indicator to the regression model (5). The social interactions parameter is then identified on within region differences in the share satisfying program criteria. Results indicate that the social interactions parameter in the sub-sample aged 50-51 increases slightly but insignificantly and that there is no change in the corresponding parameter in the sub-sample aged 48-49. The second row in panel D investigates the potential bias due to unobserved individual heterogeneity by omitting a powerful individual characteristic reflecting previous earnings. The idea of this sensitivity analysis is, that because previous earnings are highly correlated with the individuals' success on the labor market, we can investigate the potential for omitted variables to account for the result. It turns out that the identification strategy is very robust to omitting the log of previous daily earnings. This suggests that the results are not sensitive to unmeasured characteristics at the individual level. The paper has provided a potential explanation for this strong degree of robustness in table 5. Because there is no REBP specific change in the correlation between the log of previous daily earnings, results are not affected by the presence of this regressor in the model.

Panel D investigates the sensitivity of the results with respect to the choice of a linear model for the outcome. The first row applies the logit model to the indicator reflecting whether the unemployment spell has exceeded 6 months or not - the main outcome indicator used so far. Results indicate that the findings reported above are not affected at the qualitative level. The social interactions coefficients are significantly different from zero. However, the quantitative 
importance of social interactions is less strong in the logit model when compared to the linear probability model. This is due to the fact that the logit density is relatively low at the mean of the dependent variable. The second row in panel E studies the relevance of social interactions in explaining the unemployment outflow rate in the Cox proportional hazard model. Results indicate that the outflow rate is lower for spells in reference groups with a higher share of entitled individuals both, in the age group 50-51 and 48-49. An increase by one standard deviation in the share entitled to the program reduces the outflow rate between 9-18 percent.

In sum, table 7 documents that the finding of a change in the correlation between individual unemployment duration outcomes and the entitlement to REBP in the reference group is a robust, statistically significant, and quantitatively important phenomenon.

Policy Implications One of the major advantages of this new approach to identifying social interactions is that it allows to discuss directly the relevance of social interactions for economic policy. According to the evidence in Table 6, the social spillovers are equally strong in the entitled and in the non-entitled sample for the construction inflow. Thus, it is possible to impose this restriction and estimate the model (4) that contains the direct of REBP in addition to the social spillover effects of REBP on the probability of long-term unemployment. Results in table 8 indicate that the probability of long-term unemployment drops by 1.1 percentage points for non-entitled spells in treated regions when REBP is implemented - evaluated at the mean share satisfying REBP eligibility criteria (coefficient 'During ${ }^{*}$ Treated region'). In contrast, there is an increase by 2.7 percentage points for entitled individuals (coefficient 'During * Treated region * Aged 50-51'). The role of social interactions can be deduced by the coefficient 'During * Treated region * Share satisfying REBP criteria'. When comparing entitled or non-entitled individuals in treated regions to similar individuals in control regions or similar individuals in different groups, social interactions are important. For instance, the increase in the probability of long-term unemployment for the entitled individual in the group with average entitlement to REBP compared to control regions is $1.6(=-1.1+2.7)$ percentage points. On the other hand, the individual in a reference group with a one standard deviation higher share satisfying REBP criteria is estimated to experience an increase by $4.8(=1.6+3.2)$ percentage points compared to an individual with similar reference group composition in control regions. The estimates also imply that some entitled individuals are leaving unemployment quicker than comparable individuals in control regions, i.e. those in reference groups with a low share satisfying REBP criteria.

Table 8 
Moreover, the results in table 8 also allow to infer the structural social interactions parameter $\beta_{1}$ that links individual outcomes with group average outcomes. The coefficient 'During * Treated region * Age 50-51' estimates the effect of REBP holding group composition constant, i.e. the estimate of $\beta_{2}^{R}-\beta_{2}$ is 2.7. The coefficient 'During * Treated region * Share entitled satisfying REBP criteria' estimates $\left(\beta_{2}^{R}-\beta_{2}\right) \frac{\beta_{1}}{1-\beta_{1}}=3.2$. This implies that individual outcomes will change at least by $\widehat{\beta}_{1}=.54$ due to a change in group outcomes by one standard deviation. This indicates that social interactions are relevant determinants of unemployment. On the other hand, there is some evidence that social interactions are more relevant for outcomes that are determined outside markets. For instance, in the context of information acquisition, the field experiment in Duflo and Saez (2003) identifies a social spillover effect of about .75.

This analysis shows that social interactions are important in the design of unemployment benefit systems. For instance, the age related unemployment duration benefit schemes that were introduced by a number of European countries - Germany, Austria, France - in the 1980s can be expected to have increased also the unemployment duration of non-affected age groups. In the U.S. such selective benefit duration schemes are uncommon. However, in case of worsening labor market conditions it is possible that Congress enacts Temporary Extensions of Unemployment Compensation. The present analysis indicates that such temporary extensions may also increase the duration of unemployment of those individuals out of work who are not eligible for unemployment compensation by increasing unemployment duration of entitled individuals. The implication of this is that unemployment benefit policy needs to consider not only the outcomes of the entitled but also the outcomes of the non-entitled groups.

\section{Conclusions}

This paper studies the relevance of social interactions in labor supply decisions by using detailed information on a partial-population intervention in unemployment insurance. In 1988, the Austrian government extended the duration of regular unemployment benefits (REBP) from 30 weeks to 209 weeks for individuals aged 50 or older living in certain regions with continuous work history. This paper argues that this partial-population intervention allows identification of endogenous social interactions based on outcome data.

The main idea is that this policy change affects entitled individuals in two ways if social interactions are relevant. Besides the direct effect on individual decision making due to making unemployment more attractive, the policy is expected to affect unemployment via the composition of the reference group with respect to entitlement to the policy. Moreover, this policy change should also affect individuals who are not entitled via the average entitlement to REBP in the reference group. These two implications of social interactions are studied by focusing 
on the reference group comprising former workplace colleagues.

Results indicate that there is a strong effect of REBP on labor supply decisions that operates via the composition of the reference group with respect to REBP entitlement. This effect is present not only for individuals who are entitled to REBP but also for individuals who are not entitled to REBP. Second, the policy implications of social interactions are discussed by separating the effect of REBP on labor supply decisions with and without social interactions. Moreover, results show that there is a strong increase in the variance of the effects of labor market policy due to social interactions. 


\section{References}

[1] Akerlof, George A. (1997). Social Distance and Social Decisions. Econometrica 65(5): 1005-1027.

[2] Bertrand, Marianne, Luttmer, Erzo F.P. and Sendhil Mullainathan (2000). Network Effects and Welfare Cultures, Quarterly Journal of Economics, 115(3), 1019-1055.

[3] Brock, William A. and Steven N. Durlauf (2001). Interactions-Based Models, in Heckman, James J. and Edward Leamer (eds.), Handbook of Econometrics, Vol. 5, Amsterdam: North-Holland.

[4] Card, David E. and Phillip B. Levine (2000). Extended Benefits and the Duration of UI Spells: Evidence from the New Jersey Extended Benefit Program. Journal of Public Economics 78: 107-138.

[5] Case, Anne C. and Lawrence F. Katz (1991). The Company You Keep: The Effect of Family and Neighborhood on Disadvantaged Youth. NBER Working Paper No. 3708. Cambridge, MA: NBER.

[6] Corcoran, Mary, Datcher, Linda, and Greg J. Duncan. (1980). Information and influence networks in labor markets. In Duncan Greg J. and James Morgan (eds.). Five Thousand American Families: Patterns of Economic Progress, Vol. 7. Institute For Social Research: Ann Arbor, MI: 1-37.

[7] Duflo, Esther and Emmanuel Saez (2003). The Role of Information and Social Interactions in Retirement Plan Decisions: Evidence from a Randomized Experiment, Quarterly Journal of Economics, forthcoming.

[8] Falk, Armin and Urs Fischbacher (2002). "Crime" in the Lab - Detecting Social Interaction. European Economic Review 46, 859-869.

[9] Glaeser, Edward L., Sacerdote, Bruce, and José A. Scheinkman (1996). Crime and Social Interactions. Quarterly Journal of Economics 111(2): 507-548.

[10] Granovetter, Mark S. (1995). Getting a Job: A Study of Contacts and Careers. Harvard University Press: Cambridge, MA.

[11] Katz, Lawrence F. and Bruce Meyer (1990). Unemployment Insurance, Recall Expectations, and Unemployment Outcomes. Quarterly Journal of Economics 105(4): 973-1002. 
[12] Katz, Lawrence F., Kling, James, and James Liebman (2001). Moving to Opportunity in Boston: Early Results of a Randomized Mobility Experiment. Quarterly Journal of Economics, 607-654.

[13] Krauth, Brian (2001). Social Interactions, Thresholds, and Unemployment in Neighborhoods. Mimeo. Simon Fraser University.

[14] Lalive, Rafael and Josef Zweimüller (2002). Benefit Entitlement and Unemployment Duration: Accounting for Policy Endogeneity. IEW Working Paper No. 112. University of Zürich.

[15] Manski, Charles F. (1993). Identification of Endogenous Social Interactions: The Reflection Problem. Review of Economic Studies 60(3): 531-542.

[16] Manski, Charles F. (2000). Economic Analysis of Social Interactions. Journal of Economic Perspectives 14(3), 115-136.

[17] Meyer, Bruce (1995). Natural and Quasi-Experiments in Economics. Journal of Business and Economic Statistics 13(2), 151-161.

[18] Montgomery, James D. (1991). Social networks and labor-market outcomes: toward an economic analysis. American Economic Review 81(5): 1408-1418.

[19] Mortensen, Dale (1977). Unemployment Insurance and Job Search Decisions. Industrial and Labor Relations Review 30, 505-517.

[20] Moulton, Brent R. (1990). An Illustration of a Pitfall in Estimating the Effects of Aggregate Variables on Micro Units. Review of Economics and Statistics 72(2): 334-338.

[21] Moffitt, Robert A. (1999). Econometric Methods for Labor Market Analysis. In Ashenfelter, Orley and David Card. Handbook of Labor Economics, Vol. III. North-Holland: Amsterdam.

[22] Moffitt, Robert A. (2001). Policy Interventions, Low Level Equilibria, and Social Interactions. in: Durlauf, Steven N. and H. Peyton Young (eds.). Social Dynamics. Cambridge, Massachusetts: MIT Press.

[23] OECD (2000), OECD Employment Outlook, Paris.

[24] Sacerdote, Bruce (2001). Peer Effects with Random Assignment: Results for Dartmouth Roommates. Quarterly Journal of Economics 116(2): 681-704. 
[25] Stutzer, Alois and Rafael Lalive (2001). The role of social norms in job searching and subjective well-being. Mimeo, University of Zurich.

[26] Topa, Giorgio (2001). Social Interactions, Local Spillovers and Unemployment. Review of Economic Studies 68(2): 261-295.

[27] Topa, Giorgio, and Timothy G. Conley (2002). Socio-Economic Distance and Spatial Patterns in Unemployment. Journal of Applied Econometrics 17: 303-327.

[28] Van den Berg, Gerard (1990). Nonstationarity in Job Search Theory. Review of Economic Studies 57, 255-277.

[29] White, Halbert (1980). A heteroskedasticity-consistent covariance matrix estimator and a direct test for heteroskedasticity. Econometrica 48, 817-830. 
Figure 1 : GDP growth in Austria, 1980-1998

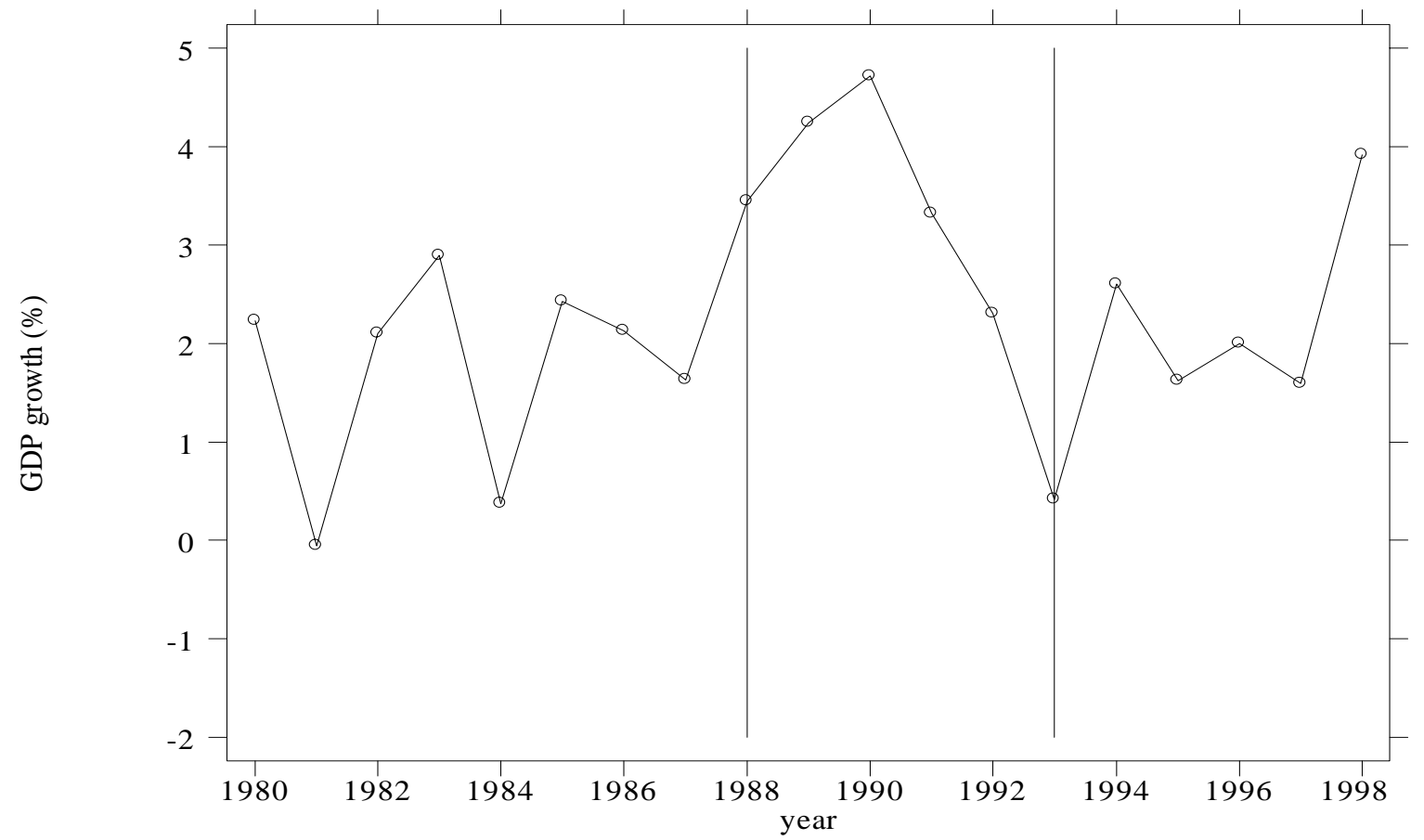

Notes: $\quad$ Vertical bars indicate start of REBP and end of REBP.

Source: Austrian Institute of Economic Research (WIFO), own calculations. 
Figure 2 : Employment in treated regions divided by employment in control regions age group 40-44, by industry

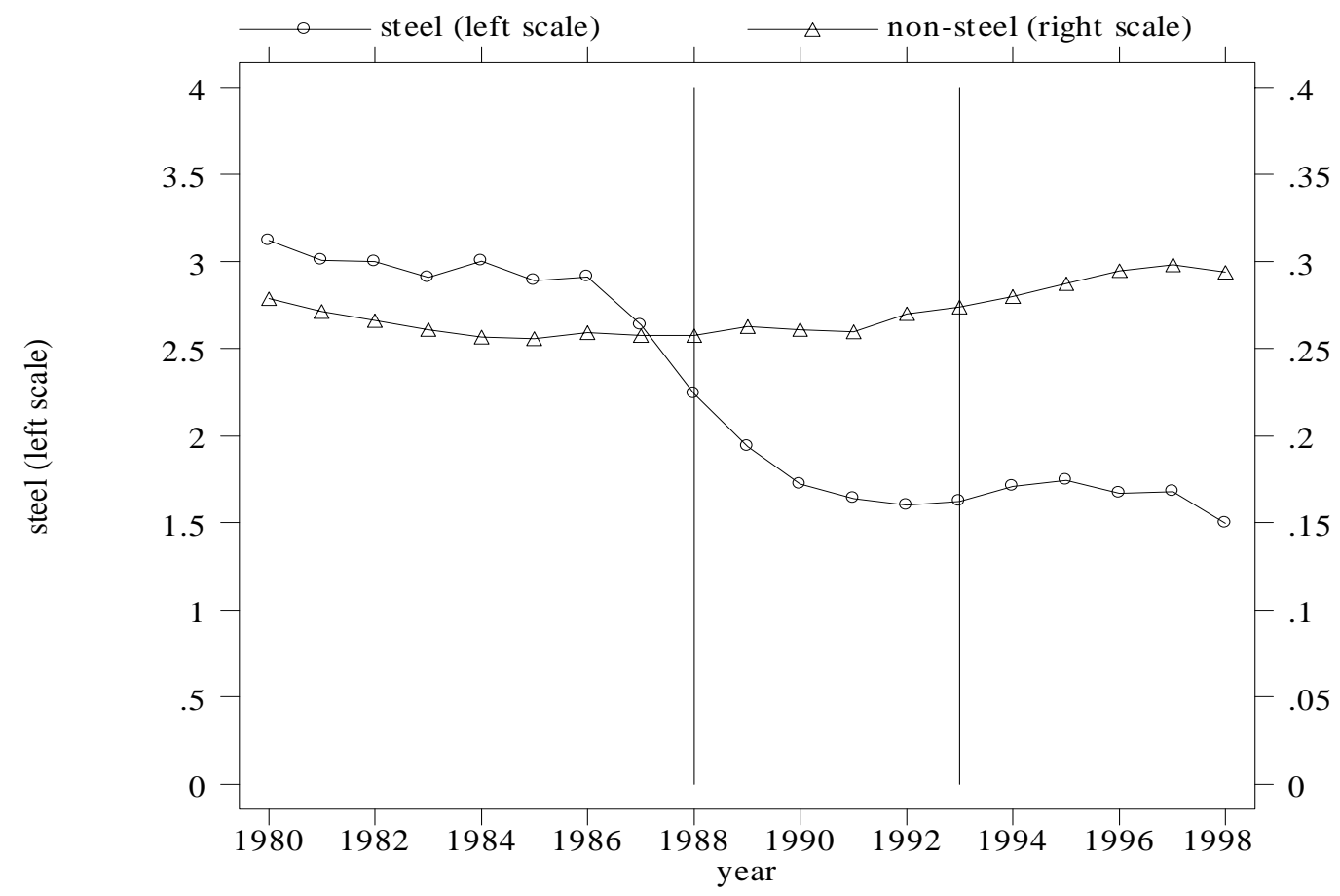
experience $>.7$.

Source: $\quad$ Own calculations, based on Austrian Social Security Data. 
Figure 3 : Definition of reference group

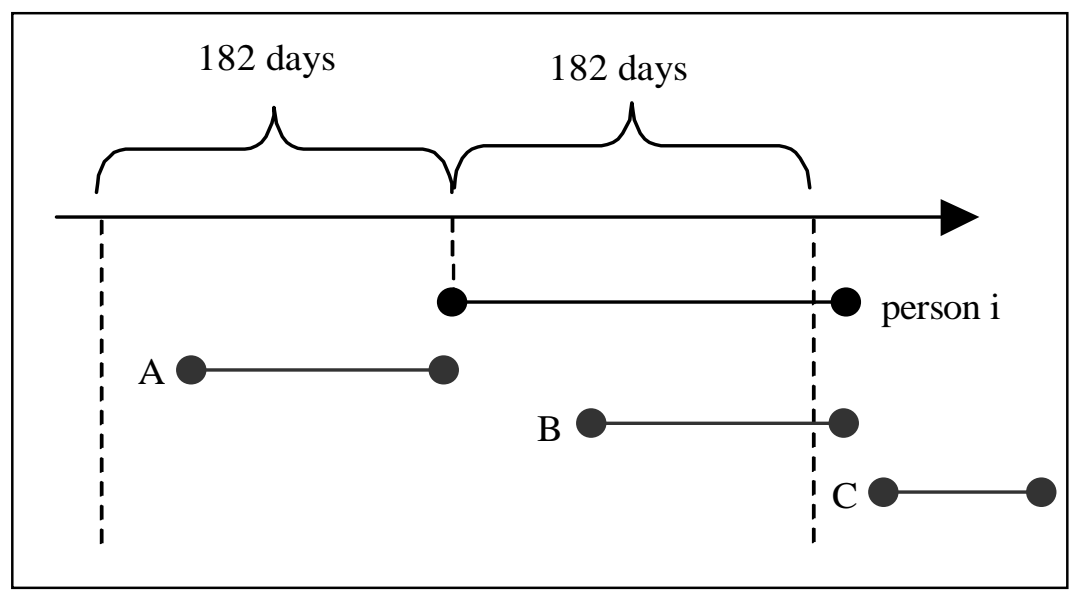


Table 1 : Risk of long-term unemployment and the REBP

Non-steel inflow

Before REBP During REBP Time effect

Treated Regions

Age 50-51

$\begin{array}{ccc}.090 & .167 & .077 \\ {[1251]} & {[2662]} & (.011) \\ .086 & .066 & -.019 \\ {[1447]} & {[2485]} & (.009)\end{array}$

Age effect

.005

.101

.096

$(.011)$

$(.009)$

$(.014)$

Control Regions

Age 50-51

.062

.081

.019

[4328]

[8649]

$(.005)$

Age 48-49

.069

.081

.011

[5109]

[9438]

(.005)

Age effect

$$
-.008
$$

.000

.008

(.005)

(.004)

(.007)

REBP Effect

.088

(.015)

\footnotetext{
Notes: Standard error in parentheses; number of observations in brackets. Risk of long-term unemployment $=$ share of spells in cell that last longer than 6 months.

Source: Own calculations, based on Austrian Social Security data.
} 


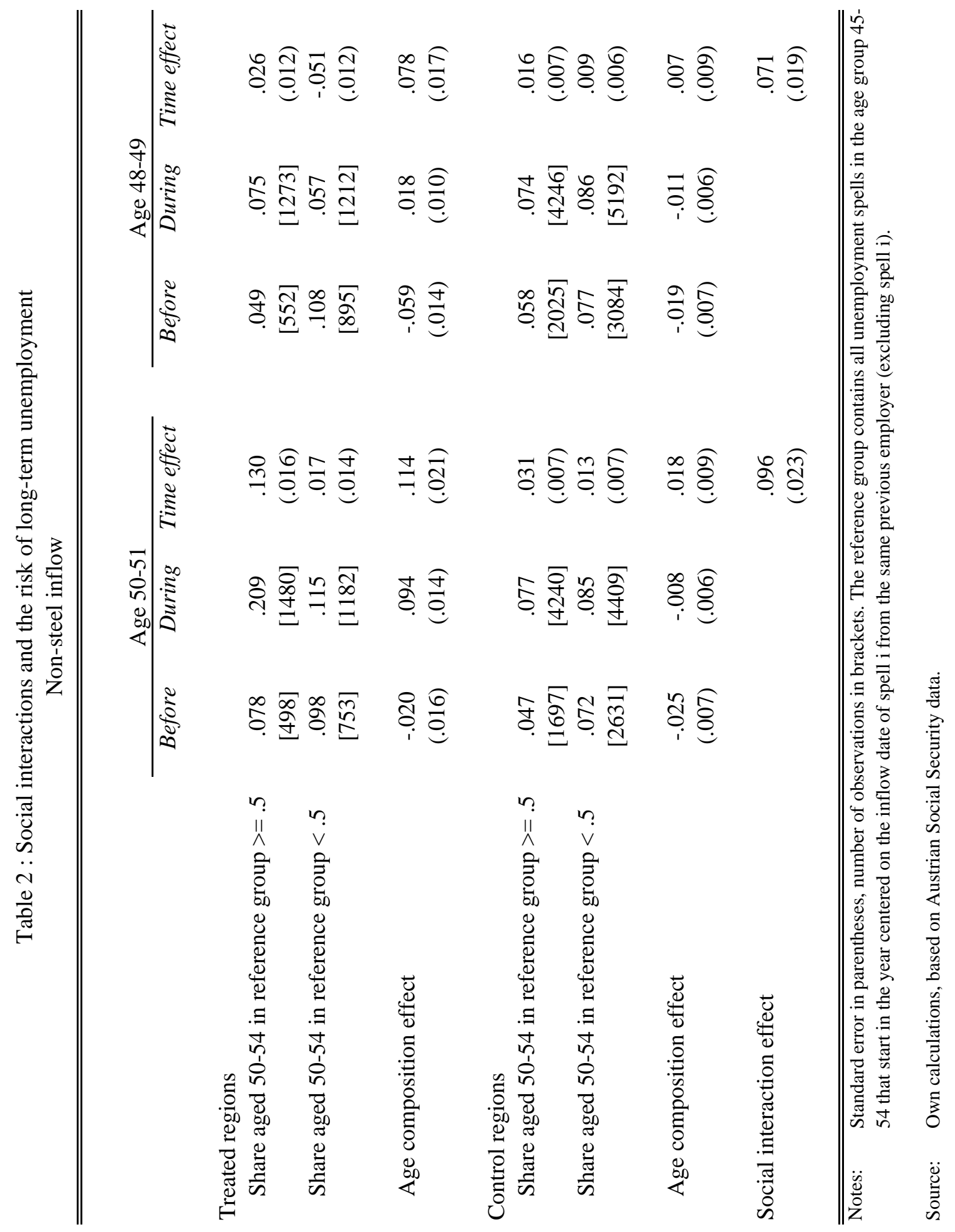


Table 3 : Social interactions in unemployment

Dependent variable : spell lasts longer than 6 months

linear probability estimates

\begin{tabular}{|c|c|c|c|c|}
\hline & \multicolumn{2}{|c|}{ Age $50-51$} & \multicolumn{2}{|c|}{ Age $48-49$} \\
\hline & Coeff. & $z$-Value & Coeff. & $z$-Value \\
\hline Share aged $50-54$ & -.003 & -.84 & -.002 & -.50 \\
\hline Treated region $*$ Share aged $50-54$ & -.008 & -.76 & -.019 & -2.24 \\
\hline During * Share aged $50-54$ & .010 & 2.10 & .003 & .61 \\
\hline During $*$ Treated region $*$ Share aged $50-54$ & .045 & 2.61 & .022 & 2.17 \\
\hline Treated region & .004 & .40 & -.008 & -.83 \\
\hline During & -.014 & -2.30 & -.017 & -2.99 \\
\hline During $*$ Treated region & .040 & 2.74 & -.028 & -2.45 \\
\hline Firm characteristics & $\mathrm{Ye}$ & & $\mathrm{Ye}$ & \\
\hline Individual characteristics & $\mathrm{Ye}$ & & $\mathrm{Ye}$ & \\
\hline Adjusted $\mathrm{R}^{2}$ & .14 & & .1 & \\
\hline Number of observations & 1685 & & 18 & 79 \\
\hline
\end{tabular}

\footnotetext{
Notes: $\quad$ z-values are based on robust standard errors that account for clustering (previous employer) and heteroskedasticity. Share aged 50-54 is standardized. Firm characteristics are $\log$ (number of other individuals flowing in from same firm in year surrounding inflow date of person $i$, $\log$ (firm size), $\log$ (mean(earnings)), workers aged $50-54$ as a percentage of workers aged 45 54 ; measured in the month before the inflow date of person $i$, and industry affiliation of the employer. Individual characteristics are age, marital status, education, white collar, nationality, experience in previous 10 years, $\log$ (average daily earnings in previous job). Additionally, the regional unemployment rate in the age group 45-54 and distance to nearest community in control region for TR spells, and -distance to nearest community in treated region for CR spells are included.
}

Source: $\quad$ Own calculations, based on Austrian Social Security data. 
Table 4 : Is the effect solely due to REBP entitlement?

Dependent variable : spell lasts longer than 6 months

linear probability estimates

\begin{tabular}{|c|c|c|c|c|}
\hline & \multirow{2}{*}{\multicolumn{2}{|c|}{$\begin{array}{l}\text { Age 50-51 } \\
\text { Coeff. z-Value }\end{array}$}} & \multicolumn{2}{|c|}{ Age $48-49$} \\
\hline & & & Coeff. & z-Value \\
\hline Share satisfying REBP criteria & -.002 & -.57 & -.003 & -.69 \\
\hline Treated region $*$ Share satisfying REBP criteria & -.011 & -.98 & -.016 & -1.82 \\
\hline During * Share satisfying REBP criteria & .007 & 1.55 & .004 & .86 \\
\hline During * Treated region * Share satisfying REBP criteria & .057 & 3.17 & .017 & 1.60 \\
\hline Rest & -.005 & -1.01 & .001 & .15 \\
\hline Treated region $*$ Rest & .001 & .05 & -.022 & -2.17 \\
\hline During * Rest & .012 & 2.13 & -.001 & -.22 \\
\hline During $*$ Treated region $*$ Rest & -.011 & -.81 & .029 & 2.43 \\
\hline Treated region & .006 & .55 & -.010 & -1.06 \\
\hline During & -.013 & -2.04 & -.018 & -3.03 \\
\hline During $*$ Treated region & .034 & 2.35 & -.025 & -2.26 \\
\hline \multirow{2}{*}{$\begin{array}{l}\text { Firm characteristics } \\
\text { Individual characteristics }\end{array}$} & \multicolumn{2}{|c|}{ Yes } & \multicolumn{2}{|c|}{ Yes } \\
\hline & \multicolumn{2}{|c|}{ Yes } & \multicolumn{2}{|c|}{ Yes } \\
\hline \multirow{2}{*}{$\begin{array}{l}\text { Adjusted } \mathrm{R}^{2} \\
\text { Number of observations }\end{array}$} & \multirow{2}{*}{\multicolumn{2}{|c|}{$\begin{array}{c}.148 \\
16890\end{array}$}} & \multicolumn{2}{|c|}{.106} \\
\hline & & & 184 & \\
\hline \multicolumn{5}{|c|}{$\begin{array}{l}\text { Notes: } \\
\text { z-values are based on robust standard errors that account for clustering (previous employer) and } \\
\text { heteroskedasticity. 'Share satisfying REBP criteria' is the share in the reference group satisfying the REBP } \\
\text { entitlement criteria, that is, aged } 50 \text { or older, ratio actual to potential experience exceeding .7, and residence in } \\
\text { TR (residence in CR for spells in CR). 'Rest' is the difference between 'Share aged } 50-54 \text { ' and 'Others entitled', } \\
\text { i.e. the share of spells in the reference group who do not satisfy either the previous work criterion or the } \\
\text { location of residence criterion, or both. See notes for table } 3 \text { for a list of firm and individual characteristics. }\end{array}$} \\
\hline
\end{tabular}

Source: Own calculations, based on Austrian Social Security data. 


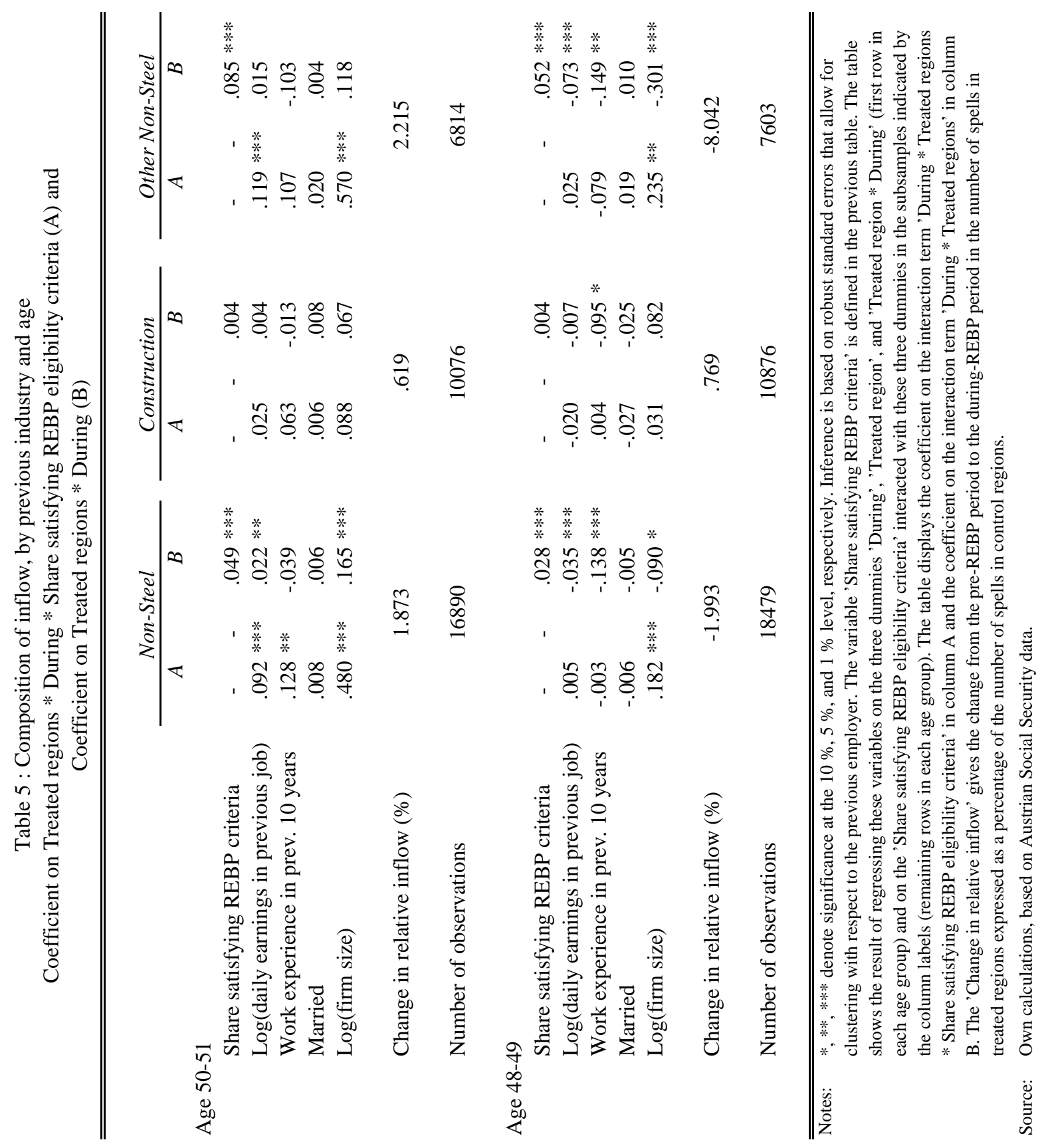




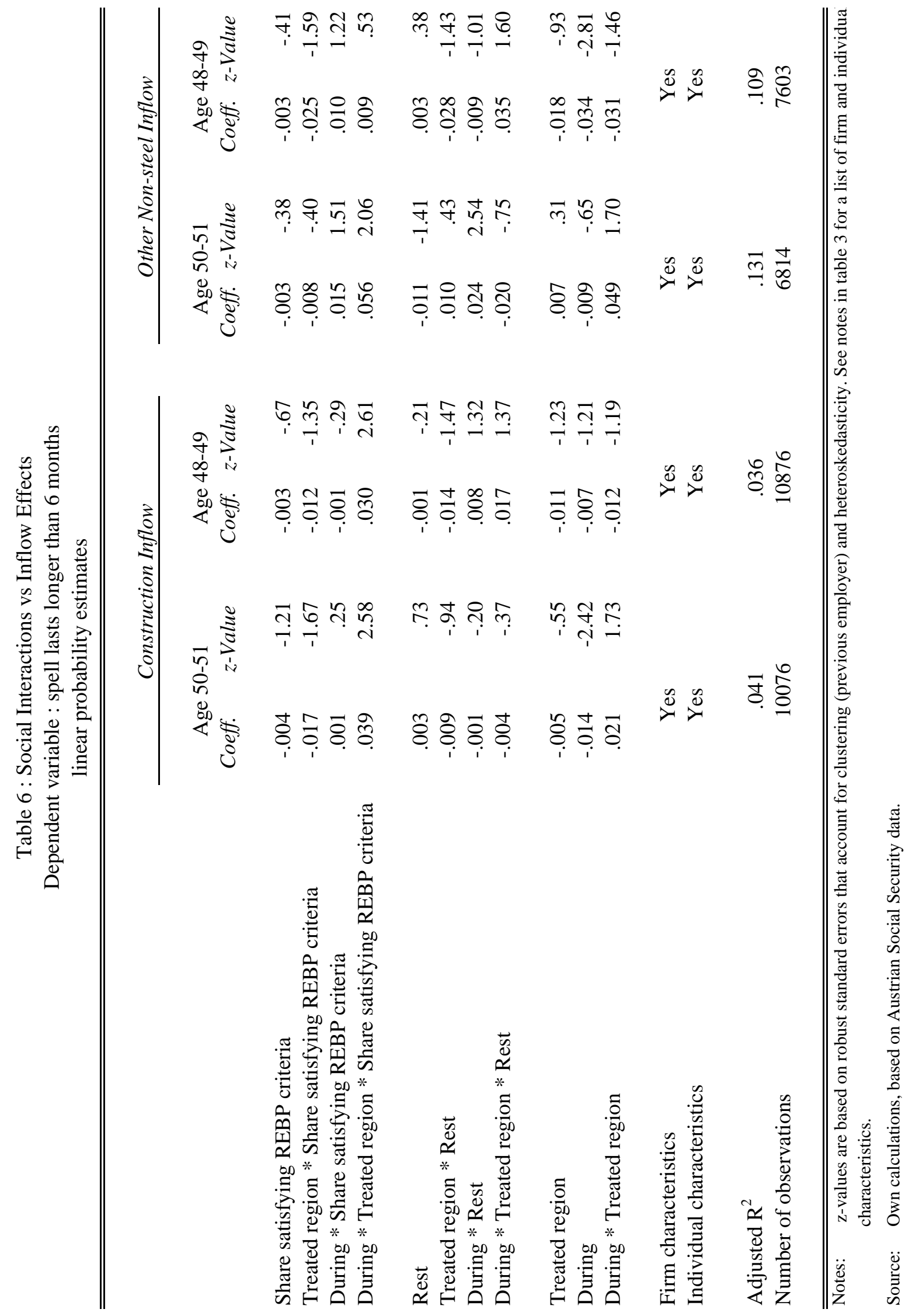


Table 7 : Sensitivity analysis

Based on Construction Inflow

Coefficient: Treated region * During * Share satisfying REBP criteria

Baseline result

A. Anticipation effects

During period starts February 27, 1988

Exclude spells aged 51 or 49

\section{B. Firm decisions}

Share satisfying REBP criteria before spell i

Share satisfying REBP criteria after spell i

C. Measurement issues

Add region effects, interacted with 'During' indicator

Omit $\log$ (daily earnings)

D. Non-linear models

Marginal effect from Logit

Effect on log exit hazard
Age 50-51

Coeff. z-Value

.039

2.58

$\begin{array}{ll}.039 & 2.59\end{array}$

$.038 \quad 3.09$

.027

.028

2.36

$\begin{array}{llll}.034 & 2.40 & .022 & 1.90 \\ .030 & 2.22 & .027 & 2.29\end{array}$

$\begin{array}{llll}.046 & 2.87 & .029 & 2.38\end{array}$

$\begin{array}{llll}.038 & 2.56 & .031 & 2.66\end{array}$

$\begin{array}{llll}.019 & 2.63 & .021 & 2.81\end{array}$

$\begin{array}{llll}-.193 & -2.91 & -.097 & -1.69\end{array}$

Notes: $\quad$ z-values are based on robust standard errors that account for clustering (previous employer) and heteroskedasticity. This table reports the interaction term 'Treated region * During * Share satisfying REBP criteria' from separate regressions following the specification in table 6 .

Source: Own calculations, based on Austrian Social Security data. 
Table 8 : Direct effects vs Social spillover effects of REBP

Dependent variable : spell lasts longer than 6 months

linear probability estimates

\begin{tabular}{|c|c|c|}
\hline & Coeff. & $z$-Value \\
\hline Share satisfying REBP criteria & -.005 & -1.52 \\
\hline Treated region * Share satisfying REBP criteria & -.012 & -1.70 \\
\hline During * Share satisfying REBP criteria & -.001 & -.35 \\
\hline During * Treated region * Share satisfying REBP criteria & .032 & 3.56 \\
\hline Aged 50-51 & -.010 & -1.45 \\
\hline Treated region $*$ Aged $50-51$ & .005 & .42 \\
\hline During * Aged 50-51 & -.001 & -.18 \\
\hline During $*$ Treated region $*$ Aged 50-51 & .027 & 1.73 \\
\hline Treated region & -.008 & -.95 \\
\hline During & -.010 & -2.05 \\
\hline During * Treated region & -.011 & -1.04 \\
\hline Firm characteristics & \multicolumn{2}{|c|}{ Yes } \\
\hline Individual characteristics & \multicolumn{2}{|c|}{ Yes } \\
\hline Adjusted $\mathrm{R}^{2}$ & \multicolumn{2}{|c|}{.038} \\
\hline Number of observations & \multicolumn{2}{|c|}{20952} \\
\hline
\end{tabular}

\footnotetext{
Notes: $\quad$ Estimates are based on construction inflow. z-values are based on robust standard errors that account for clustering (previous employer) and heteroskedasticity. See notes to table 3 for additional information.

Source: Own calculations, based on Austrian Social Security data.
} 
Table A1 : Descriptive statistics, non-steel inflow vs construction inflow.

\begin{tabular}{|c|c|c|c|c|c|c|}
\hline & \multicolumn{2}{|c|}{ Non-steel } & \multicolumn{2}{|c|}{ Construction } & \multicolumn{2}{|c|}{ Other Non-Steel } \\
\hline & Mean & SD & Mean & SD & Mean & SD \\
\hline \multicolumn{7}{|l|}{ characteristics of reference group } \\
\hline number of spells & 24.871 & $(64.936)$ & 20.958 & $(36.219)$ & 30.558 & $(91.564)$ \\
\hline $\log$ (number of spells) & 2.223 & $(1.312)$ & 2.311 & $(1.208)$ & 2.094 & $(1.441)$ \\
\hline proportion aged $50-54$ & .448 & $(.265)$ & .453 & $(.244)$ & .440 & $(.292)$ \\
\hline proportion satisfying REBP criteria & .336 & $(.259)$ & .343 & $(.240)$ & .326 & $(.284)$ \\
\hline \multicolumn{7}{|l|}{ characteristics of previous employer } \\
\hline $\log ($ firm size $)$ & 4.539 & $(1.339)$ & 4.365 & $(1.123)$ & 4.792 & $(1.568)$ \\
\hline $\log ($ average(daily earnings)) & 6.512 & $(.198)$ & 6.505 & $(.182)$ & 6.521 & $(.218)$ \\
\hline proportion aged 50-54 in 45-54 year olds & .522 & $(.234)$ & .529 & $(.241)$ & .513 & $(.222)$ \\
\hline manufacturing, excluding steel & .115 & & .000 & & .282 & \\
\hline mining & .021 & & .000 & & .050 & \\
\hline construction & .592 & & 1.000 & & .000 & \\
\hline tourism & .070 & & .000 & & .172 & \\
\hline other industries & .202 & & .000 & & .496 & \\
\hline \multicolumn{7}{|l|}{ individual characteristics } \\
\hline change in August 1989 & .417 & & .415 & & .420 & \\
\hline age & 49.940 & $(1.145)$ & 49.944 & $(1.142)$ & 49.934 & $(1.150)$ \\
\hline married & .814 & & .835 & & .783 & \\
\hline divorced or widower & .090 & & .071 & & .119 & \\
\hline single & .096 & & .094 & & .098 & \\
\hline compulsory education & .653 & & .643 & & .666 & \\
\hline apprenticeship & .342 & & .356 & & .323 & \\
\hline craftsmanship & .005 & & .001 & & .011 & \\
\hline white collar & .069 & & .021 & & .139 & \\
\hline foreign & .126 & & .135 & & .114 & \\
\hline experience in previous 10 years & 8.614 & $(1.082)$ & 8.438 & $(1.024)$ & 8.871 & (1.113) \\
\hline $\log$ (previous earnings) in AS & 6.472 & $(.267)$ & 6.470 & $(.234)$ & 6.474 & $(.309)$ \\
\hline regional unemployment rate $(\%)$ & 3.455 & $(1.607)$ & 3.332 & $(1.485)$ & 3.633 & $(1.754)$ \\
\hline distance to border (hours) & -.787 & $(1.183)$ & -.885 & $(1.163)$ & -.644 & $(1.197)$ \\
\hline number of observations & 35369 & & 20952 & & 14417 & \\
\hline
\end{tabular}

Source: Own calculations, based on Austrian Social Security data. 


\begin{tabular}{|c|c|c|c|c|c|c|c|c|}
\hline & \multicolumn{4}{|c|}{ Age $50-51$} & \multicolumn{4}{|c|}{ Age $48-49$} \\
\hline & \multicolumn{2}{|c|}{ TR } & \multicolumn{2}{|c|}{$\mathrm{CR}$} & \multicolumn{2}{|c|}{ TR } & \multicolumn{2}{|c|}{$\mathrm{CR}$} \\
\hline & Mean & SD & Mean & SD & Mean & $\mathrm{SD}$ & Mean & SD \\
\hline $\log ($ number of spells in reference group) & 2.361 & $(1.128)$ & 2.309 & $(1.219)$ & 2.317 & $(1.127)$ & 2.301 & $(1.233)$ \\
\hline $\log ($ firm size $)$ & 4.481 & $(1.046)$ & 4.339 & $(1.125)$ & 4.444 & $(1.080)$ & 4.346 & $(1.145)$ \\
\hline $\log ($ average(earnings) in firm) & 6.475 & $(.165)$ & 6.515 & $(.187)$ & 6.466 & $(.163)$ & 6.512 & $(.185)$ \\
\hline proportion aged 50-54 in $45-54$ year olds in firm & .586 & $(.225)$ & .577 & $(.224)$ & .501 & $(.255)$ & .478 & $(.245)$ \\
\hline change in August 1989 & .000 & & .488 & & .438 & & .433 & \\
\hline age & 50.959 & $(.576)$ & 50.970 & $(.575)$ & 48.982 & $(.576)$ & 49.000 & $(.580)$ \\
\hline married & .862 & & .838 & & .857 & & .822 & \\
\hline divorced or widower & .062 & & .067 & & .059 & & .078 & \\
\hline single & .076 & & .095 & & .084 & & .100 & \\
\hline compulsory education & .702 & & .645 & & .679 & & .621 & \\
\hline apprenticeship & .298 & & .354 & & .321 & & .378 & \\
\hline craftsmanship & .001 & & .001 & & .000 & & .001 & \\
\hline white collar & .015 & & .019 & & .015 & & .026 & \\
\hline foreign & .192 & & .123 & & .186 & & .121 & \\
\hline experience in previous 10 years & 8.406 & (1.027) & 8.450 & $(1.016)$ & 8.383 & (1.039) & 8.445 & $(1.027)$ \\
\hline $\log$ (previous earnings) in AS & 6.434 & $(.222)$ & 6.480 & $(.237)$ & 6.426 & $(.222)$ & 6.479 & $(.234)$ \\
\hline regional unemployment rate $(\%)$ & 3.422 & $(1.587)$ & 3.276 & $(1.448)$ & 3.413 & $(1.589)$ & 3.345 & $(1.470)$ \\
\hline distance to border (hours) & .572 & $(.263)$ & -1.218 & $(1.020)$ & .567 & $(.263)$ & -1.230 & $(1.022)$ \\
\hline number of observations & 1920 & & 8156 & & 2042 & & 8834 & \\
\hline
\end{tabular}

Notes: $\quad T R=$ resident in REBP region, $C R=$ resident in non-REBP region. The change in August 1989 is zero for spells in TR aged 50-51 because these spells were not affected by the change in potential benefit duration that occured in August 1989 (section 2). Distance to border gives the commuting time by car in hours from the community of residence to the nearest community across the border for spells in TR and the negative of this time for spells in CR.

Source: Own calculations, based on Austrian Social Security data. 


\begin{tabular}{|c|c|c|c|c|c|c|c|c|}
\hline & \multicolumn{2}{|c|}{ Age $50-51$} & \multicolumn{2}{|c|}{ Age $48-49$} & \multicolumn{2}{|c|}{ Age $50-51$} & \multicolumn{2}{|c|}{ Age 48-49 } \\
\hline & Coeff. & z-Value & Coeff. & z-Value & Coeff. & $z$-Value & Coeff. & $z$-Value \\
\hline Share satisfying REBP criteria & -.004 & -1.21 & -.003 & -.67 & -.003 & -.38 & -.003 & -.41 \\
\hline Treated region * Share satisfying REBP $\mathrm{cr}$ & -.017 & -1.67 & -.012 & -1.35 & -.008 & -.40 & -.025 & -1.59 \\
\hline During * Share satisfying REBP criteria & .001 & .25 & -.001 & -.29 & .015 & 1.51 & .010 & 1.22 \\
\hline During $*$ Treated region $*$ Share satisfying & .039 & 2.58 & .030 & 2.61 & .056 & 2.06 & .009 & .53 \\
\hline Rest & .003 & .73 & -.001 & -.21 & -.011 & -1.41 & .003 & .38 \\
\hline Treated region $*$ Rest & -.009 & -.94 & -.014 & -1.47 & .010 & .43 & -.028 & -1.43 \\
\hline During * Rest & -.001 & -.20 & .008 & 1.32 & .024 & 2.54 & -.009 & -1.01 \\
\hline During $*$ Treated region $*$ Rest & -.004 & -.37 & .017 & 1.37 & -.020 & -.75 & .035 & 1.60 \\
\hline Treated region & -.005 & -.55 & -.011 & -1.23 & .007 & .31 & -.018 & -.93 \\
\hline During & -.014 & -2.42 & -.007 & -1.21 & -.009 & -.65 & -.034 & -2.81 \\
\hline During $*$ Treated region & .021 & 1.73 & -.012 & -1.19 & .049 & 1.70 & -.031 & -1.46 \\
\hline $\log$ (number of spells in reference group) & -.017 & -5.24 & -.014 & -5.02 & -.004 & -.62 & -.001 & -.28 \\
\hline $\log ($ firm size $)$ & .017 & 4.25 & .012 & 4.13 & .010 & 1.86 & .012 & 2.84 \\
\hline $\log ($ average(earnings) in firm) & .053 & 3.49 & .027 & 2.16 & .108 & 3.33 & .020 & .76 \\
\hline proportion aged $50-54$ in $45-54$ & -.030 & -3.11 & -.009 & -1.19 & -.058 & -2.51 & .016 & 1.00 \\
\hline change in August 1989 & .006 & 1.06 & .002 & .36 & .030 & 2.09 & .032 & 3.06 \\
\hline age & .002 & .75 & .004 & 1.40 & .011 & 1.48 & .007 & 1.15 \\
\hline married & -.025 & -3.17 & -.022 & -3.04 & -.072 & -4.22 & -.056 & -3.91 \\
\hline divorced / widower & -.002 & -.13 & .023 & 1.87 & -.024 & -1.08 & -.004 & -.22 \\
\hline apprenticeship & -.002 & -.40 & -.002 & -.48 & .037 & 3.11 & .012 & 1.35 \\
\hline craftsmanship & .150 & 1.57 & .282 & 2.15 & .049 & .88 & .120 & 2.29 \\
\hline white collar & .154 & 5.51 & .116 & 5.05 & .240 & 11.62 & .234 & 13.73 \\
\hline foreign & -.015 & -2.47 & -.011 & -1.95 & -.049 & -3.62 & -.008 & -.69 \\
\hline experience in previous 10 years & -.011 & -4.50 & -.008 & -3.66 & .018 & 3.61 & .006 & 1.72 \\
\hline $\log$ (previous earnings) in AS & -.042 & -3.26 & -.033 & -2.57 & -.089 & -3.73 & -.016 & -.86 \\
\hline manufacturing, excluding steel & & & & & .052 & 1.81 & .057 & 2.91 \\
\hline mining & & & & & -.060 & -2.62 & -.048 & -3.37 \\
\hline tourism & & & & & .029 & 1.90 & .038 & 3.10 \\
\hline unemployment rate & .009 & 4.20 & .011 & 6.63 & .023 & 6.34 & .014 & 5.55 \\
\hline distance to border & .009 & 5.63 & .010 & 6.21 & .012 & 2.51 & .015 & 4.48 \\
\hline constant & .083 & 2.77 & .070 & 2.73 & .087 & 1.58 & .113 & 2.71 \\
\hline Adjusted $\mathrm{R}^{2}$ & .04 & & & & .13 & & .10 & \\
\hline Number of observations & 100 & & & & 68 & & 760 & \\
\hline
\end{tabular}




\section{IZA Discussion Papers}

\begin{tabular}{|c|c|c|c|c|}
\hline No. & Author(s) & Title & Area & Date \\
\hline 790 & $\begin{array}{l}\text { A. Cigno } \\
\text { A. Luporini } \\
\text { A. Pettini }\end{array}$ & $\begin{array}{l}\text { Hidden Information Problems in the Design of } \\
\text { Family Allowances }\end{array}$ & 3 & $06 / 03$ \\
\hline 791 & M. Güell & $\begin{array}{l}\text { Fixed-Term Contracts and the Duration } \\
\text { Distribution of Unemployment }\end{array}$ & 1 & 06/03 \\
\hline 792 & $\begin{array}{l}\text { L. Borghans } \\
\text { B. ter Weel }\end{array}$ & $\begin{array}{l}\text { What Happens When Agent T Gets a } \\
\text { Computer? The Labor Market Impact of Cost } \\
\text { Efficient Computer Adoption }\end{array}$ & 5 & 06/03 \\
\hline 793 & T. Palokangas & $\begin{array}{l}\text { Foreign Direct Investment, Labour Market } \\
\text { Regulation and Self-Interested Governments }\end{array}$ & 3 & $06 / 03$ \\
\hline 794 & $\begin{array}{l}\text { P. Frijters } \\
\text { M. A. Shields } \\
\text { S. Wheatley Price }\end{array}$ & $\begin{array}{l}\text { Investigating the Quitting Decision of Nurses: } \\
\text { Panel Data Evidence from the British National } \\
\text { Health Service }\end{array}$ & 1 & 06/03 \\
\hline 795 & B. T. Hirsch & $\begin{array}{l}\text { Reconsidering Union Wage Effects: Surveying } \\
\text { New Evidence on an Old Topic }\end{array}$ & 3 & $06 / 03$ \\
\hline 796 & P. Apps & Gender, Time Use and Models of the Household & 5 & 06/03 \\
\hline 797 & $\begin{array}{l}\text { E. Bratberg } \\
\varnothing . \text { A. Nilsen } \\
\text { K. Vaage }\end{array}$ & $\begin{array}{l}\text { Assessing Changes in Intergenerational } \\
\text { Earnings Mobility }\end{array}$ & 2 & $06 / 03$ \\
\hline 798 & $\begin{array}{l}\text { J. J. Heckman } \\
\text { J. A. Smith }\end{array}$ & $\begin{array}{l}\text { The Determinants of Participation in a Social } \\
\text { Program: Evidence from a Prototypical Job } \\
\text { Training Program }\end{array}$ & 6 & 06/03 \\
\hline 799 & R. A. Hart & $\begin{array}{l}\text { General Human Capital and Employment } \\
\text { Adjustment in the Great Depression: } \\
\text { Apprentices and Journeymen in UK Engineering }\end{array}$ & 2 & 06/03 \\
\hline 800 & $\begin{array}{l}\text { T. Beissinger } \\
\text { C. Knoppik }\end{array}$ & $\begin{array}{l}\text { Sind Nominallöhne starr? Neuere Evidenz und } \\
\text { wirtschaftspolitische Implikationen }\end{array}$ & 7 & 06/03 \\
\hline 801 & A. Launov & $\begin{array}{l}\text { A Study of the Austrian Labor Market Dynamics } \\
\text { Using a Model of Search Equilibrium }\end{array}$ & 2 & $06 / 03$ \\
\hline 802 & $\begin{array}{l}\text { H. Antecol } \\
\text { P. Kuhn } \\
\text { S. J. Trejo }\end{array}$ & $\begin{array}{l}\text { Assimilation via Prices or Quantities? Labor } \\
\text { Market Institutions and Immigrant Earnings } \\
\text { Growth in Australia, Canada, and the United } \\
\text { States }\end{array}$ & 1 & 06/03 \\
\hline 803 & R. Lalive & Social Interactions in Unemployment & 3 & $06 / 03$ \\
\hline
\end{tabular}

An updated list of IZA Discussion Papers is available on the center's homepage www.iza.org. 